\title{
Graphene quantum dots decorated with magnetic nanoparticles: Synthesis, electrodeposition, characterization and application as an electrochemical sensor towards determination of some amino acids at physiological pH
}

\author{
Mohammad Hasanzadeh a,b*, Ayub karimzadeh c, Nasrin Shadjou e,f, Ahad Mokhtarzadeh d,c, Leyla Bageri \\ a, Sattar Sadeghi ${ }^{\text {c,d }}$, Soltanali Mahbub ${ }^{\text {c }}$ \\ ${ }^{a}$ Drug Applied Research Center, Tabriz University of Medical Sciences, Tabriz 51664, Iran. \\ ${ }^{\mathrm{b}}$ Pharmaceutical Analysis Research Center, Tabriz University of Medical Sciences, Tabriz 51664, Iran. \\ ${ }^{\mathrm{c}}$ Department of Biochemistry, Higher Education Institute of Rab-Rashid, Tabriz, Iran \\ d School of Medicine, Gonabad University of Medical Sciences, Gonabad, Iran \\ e Department of Nanochemistry, Nano Technology Research Center, Urmia University, Urmia 57154, Iran. \\ ${ }^{\mathrm{f}}$ Department of Nano Technology, Faculty of Science, Urmia University, Urmia 57154, Iran.
}

\begin{abstract}
Corresponding Author
E-mail address: (*) mhmmd_hasanzadeh@yahoo.com, hasanzadehm@tbzmed.ac.ir

Drug Applied Research Center, Tabriz University of Medical Sciences, Tabriz 51664, Iran.
\end{abstract}

Tel: +98(41) 33363311; Fax: +98(41)33363231 


\begin{abstract}
This study reports on the synthesis and characterization of a novel nano-composite, $\mathrm{Fe}_{3} \mathrm{O}_{4}$ magnetic nanoparticles/graphene quantum dots ( $\left.\mathrm{Fe}_{3} \mathrm{O}_{4} \mathrm{MNP}-\mathrm{GQDs}\right)$, for sensing of some amino acids. For the first time, as-synthesized GQDs and $\mathrm{Fe}_{3} \mathrm{O}_{4} \mathrm{MNPs}-\mathrm{GQDs}$ was electrodeposited on the glassy carbon electrode (GCE) by cyclic voltammetry (CV) regime in the potential range from -1.0 to $1.0 \mathrm{~V}$. $\mathrm{Fe}_{3} \mathrm{O}_{4} \mathrm{MNP}-\mathrm{GQDs}$ is engineered to specifically and effectively capture and enhancement the electrochemical signals of some amino acids at physiological $\mathrm{pH}$ due to the synergy among GQDs and magnetic nanoparticles. We have illustrated that the obtained $\mathrm{Fe}_{3} \mathrm{O}_{4}$ MNPs-GQDs exhibited a much higher electroactivity individual GQDs and $\mathrm{Fe}_{3} \mathrm{O}_{4} \mathrm{MNPs}$ for the electrooxidation and detection of amino acid which was about 10 fold higher than for GQDs. Magnetic and specific properties of the $\mathrm{Fe}_{3} \mathrm{O}_{4}$ MNP-GQDs can be exploited to capture and preconcentration the amino acids onto its surface, which are important for detection of multi-amino acids.
\end{abstract}

\title{
KEYWORDS
}

magnetic nanoparticle, graphene quantum dot, electrochemical sensor, amino acid. 


\section{Introduction}

Graphene quantum dots (GQDs) are nanometer-sized fragments of graphene. GQDs are a kind of OD material with characteristics deriving from both graphene and carbon dots (CDs) [1]. Taking advantage of the electrochemical properties similar to graphene, GQDs are widely used as a kind of suitable electrode material, not only in fuel cells [2], supercapacitors [3, 4], and photovoltaic cells [5], but also in the field of electrochemical sensors [6, 7]. Furthermore, GQDs with tunable sizes, ie., $2.2 \pm 0.3,2.6 \pm 0.2$, and $3 \pm 0.3 \mathrm{~nm}$, can act as multivalent redox species using cyclic voltammetry (CV) and differential pulse voltammetry (DPV) measurements, and present exciting opportunities for building electrochemical sensors [8]. More recently, GQDs have been used in the area of bioanalysis [6-9]. However, their applications in the analytical field have not been explored until now. Due to their unique properties, sensors based on GQDs can achieve a high level of performance.

GQDs increase the contact area with the analyte, so they could increase the electrochemical active surface to interact with some electroactive analytes [10]. Since the increase in geometric surface area is very important parameter in electrochemistry, therefore modification of different substrates (such as glass, carbon, graphite etc.) by GQDs can increase the rate of electrochemical reaction.

Besides the applications of GQDs, integration of nanoparticles (MNPs) into GQDs has recently become a hot topic of research due to their new and/or enhanced functionalities that cannot be achieved by either component alone, and therefore holds great promise for a wide variety of applications in catalysis, optoelectronic materials, and so on [11-14]. Magnetic nanoparticles (MNPs) especially iron oxide (either $\mathrm{Fe}_{3} \mathrm{O}_{4}$ or $\mathrm{Fe}_{2} \mathrm{O}_{3}$ ), and its nanocomposite with GQDs, were applied in enhanced optical limiting, MRI (magnetic resonance imaging), drug delivery, energy storage and removal of contaminants from wastewater [15-17]. Although a number of researchers have proposed methods for the preparation of magnetic GQDs finding applications in various fields, none of them have managed to apply these hybrids for electrochemical sensing or biosensing purposes. As far as we know, little or no attention has been paid to the use of magnetic GQDs for electrochemical sensing. Herein, for the first time, we report an electrochemical preparation of $\mathrm{Fe}_{3} \mathrm{O}_{4}$ MNPs-GQDs film and its interface for the recognition of some amino acids.

As a laboratory technique, the analysis of amino acid plays an important role in biochemical, pharmaceutical and biomedical fields. Also, amino acids exist in a free form or bound in peptides, proteins, or non-peptide bonded polymers [17]. Naturally occurring L-amino acids are required for protein synthesis and are precursors for essential molecules, such as co-enzymes and nucleic acids. Non-protein amino acids may also occur in animal tissues as metabolic intermediates or have other important functions [18-39]. Mostly, the methods were based on the technology developed by Moore and Stein, which includes post-column derivatization and detection in the visible region on an amino acid analyzer. These analyses are reliable, but costly and time-consuming. Also, although these methods have the advantages of sensitivity and accuracy, their complicated operation, limit their extensive application. There is, therefore, a need for the rapid and accurate determination of amino acids. The electrochemical methods, with respect to their sensitivity, accuracy, simplicity and ease of on-site determination, have received considerable attention for the analysis of amino acids [40-49]. The oxidation and adsorption behaviors of amino acids on electrode surfaces are relevant to the interfacial behaviors of 
biological molecules and also to the medical and industrial problems associated with the adsorption of the amino acids on the surfaces [50-52]. But, the use of bare, unmodified electrodes as electrochemical sensors for amino acids had a number of limitations. Low sensitivity and reproducibility, slow electron transfer reactions, low stability over a wide range of solution compositions and high over potential at which the electron transfer process occurs were the limitations identified.

Considering that the electrochemical method possesses unique advantages for precise control over the redox reactions, we therefore hypothesize that, electrochemical deposition of $\mathrm{Fe}_{3} \mathrm{O}_{4}$ MNP-GQDs under controllable conditions may provide an alternative approach for tailoring the surface properties of thin films. On the other hand, these improved performances encouraged us to explore the possible leading role played by the presence of $\mathrm{Fe}_{3} \mathrm{O}_{4} \mathrm{MNP}$ on the structure of GQDs. Therefore, in the present study, the magnetic graphene quantum dot $\left(\mathrm{Fe}_{3} \mathrm{O}_{4} \mathrm{MNPs}\right.$ GQDs) was synthesized successfully and characterized by using Fourier transform infrared spectroscopy (FTIR), transmission electron microscopy (TEM) and atomic force microscopy (AFM). For the first time, as-synthesized GQDs and $\mathrm{Fe}_{3} \mathrm{O}_{4}$ MNPs-GQDs was electrodeposited on GCE by cyclic voltammetry $(\mathrm{CV})$ in the potential range from -1.0 to $1.0 \mathrm{~V}$ and the prepared films were used for detection of amino acid at physiological $\mathrm{pH}$. Herein, we explore the electrocatalytical activity of $\mathrm{Fe}_{3} \mathrm{O}_{4}$ MNPs-GQDs. We have illustrated that the as-obtained $\mathrm{Fe}_{3} \mathrm{O}_{4}$ MNPs-GQDs exhibited a much higher electroactivity individual GQDs and $\mathrm{Fe}_{3} \mathrm{O}_{4} \mathrm{MNPs}$ for the electrooxidation and detection of amino acid which was about 10 fold higher than for GQDs. More importantly, a substantial $(+0.21 \mathrm{~V})$ decrease in the overvoltage of the amino acid oxidation reaction (compared to ordinary electrodes) was observed using $\mathrm{Fe}_{3} \mathrm{O}_{4} \mathrm{MNPs}-\mathrm{GQDs}$ GCE.

\section{Experimental details}

\subsection{Chemicals and reagents}

All chemicals were purchased from Merck (Darmstadt, Germany) and used without further purification. Alumina slurry was purchased from Beuhler (Illinois, USA) and raw material of amino acids was purchased from Merck (Germany). All solutions were prepared with deionized water. The stock solution of Amino acid $(0.003 \mathrm{~g} / \mathrm{mL})$ was prepared by dissolving an accurate amount of selected amino acids in an appropriate volume of $0.1 \mathrm{M}$ phosphate buffer solution (PBS), $\mathrm{pH}=7.4$ (which was also used as supporting electrolyte), and then stored in the dark place at $4{ }^{\circ} \mathrm{C}$. Additional dilute solutions were prepared daily by accurate dilution just before use. Also the other stock solutions were prepared by dissolving an accurate amount equal to molecular weight of each one in an appropriate volume of $1000 \mathrm{~mL}$ deionized water and then all stored in the dark place at $4{ }^{\circ} \mathrm{C}$.

\subsection{Apparatuses and methods}

Electrochemical measurements were carried out in a three-electrode cell setup. The system was run on a Personal Computer using NOVA1.7 software. Saturated $\mathrm{Ag} / \mathrm{AgCl}$ as a reference electrode and the counter electrode (also known as auxiliary electrode), which usually made of an inert material was platinum. All potentials were measured with respect to the $\mathrm{Ag} / \mathrm{AgCl}$ which 
was positioned as close to the working electrode as possible by means of a luggin capillary. Glassy carbon electrode (GCE) (from Azar electrode Co., Urmia, Iran) was used as the working electrode. The transmission electron microscope (TEM) images were obtained on Leo 906, Zeiss, (Germany). Atomic force microscopy (AFM) experiments were performed at contact mode by Nanowizard AFM (JPK Instruments AG, Berlin, Germany) mounted on Olympus Invert Microscope IX81 (Olympus Co., Tokyo, Japan).

\subsection{Synthesis GQDs and $\mathrm{Fe}_{3} \mathrm{O}_{4}$ MNPs-GQDs}

An easy bottom-up method was used for the preparation of GQDs. At first, GQDs were synthesized by pyrolyzing citric acid and dispersing the carbonized products into alkaline solutions. Briefly, $2 \mathrm{~g}$ of citric acid was put into a beaker and heated to $200{ }^{\circ} \mathrm{C}$ by a heating mantle until the citric acid changed to an orange liquid. Then, for preparing GQDs, $100 \mathrm{~mL}$ of 10 $\mathrm{mg} / \mathrm{mL} \mathrm{NaOH}$ solution was added into the orange homogenous liquid dropwise with continuous stirring. The obtained GQD solution was stable for at least one month at $4{ }^{\circ} \mathrm{C}$. Then, $\mathrm{The} \mathrm{Fe}_{3} \mathrm{O}_{4}$ MNPs-GQDs composites were synthesized through a one-step co-precipitation procedure. First, GQDs $(0.1 \mathrm{~g})$ was dispersed in $150 \mathrm{~mL}$ deionized water by sonication for $10 \mathrm{~min}$. Then, $1.214 \mathrm{~g}$ $\mathrm{FeCl}_{3} \cdot 6 \mathrm{H}_{2} \mathrm{O}$ was added to GQDs solution at room temperature under a nitrogen flow with vigorous stirring. Then, temperature was increased to $80{ }^{\circ} \mathrm{C}$, and $0.485 \mathrm{~g}$ of the $\mathrm{FeCl}_{2} .4 \mathrm{H}_{2} \mathrm{O}$ was added slowly to the solution containing $\mathrm{Fe}^{3+} / \mathrm{GQDs}$, which was vigorously stirred for an additional $30 \mathrm{~min}$. Finally, the ammonia solution was added dropwise to adjust the $\mathrm{pH}$ of the solution to 10 for the synthesis of magnetite $\mathrm{Fe}_{3} \mathrm{O}_{4}$ MNPs-GQDs. (See Scheme 1)

\subsection{Characterization of GQDs and $\mathrm{Fe}_{3} \mathrm{O}_{4}$ MNPs-GQDs}

Fig. 1(A and B) presents the AFM and TEM images of synthesized GQDs. The corresponding AFM image shows a single GQD monolayer thin film. Ninety percent of the particles represent dark brown color which assigned to a size range below $10 \mathrm{~nm}$. Also, the morphologies of the $\mathrm{Fe}_{3} \mathrm{O}_{4}$ MNPs-GQDs used in this work were characterized using AFM and TEM and the images are depicted in Fig. 1D and E. From these images it's found that, differing from the two dimensional layered structures of GQDs, the $\mathrm{Fe}_{3} \mathrm{O}_{4}$ MMNPs and GQDs aggregated into three dimensional structures. Most probably, as schematically depicted in Fig. 1D-F, the $\mathrm{Fe}_{3} \mathrm{O}_{4} \mathrm{MNPs}$ are surrounded by GQDs to form composite particles. The sizes of the $\mathrm{Fe}_{3} \mathrm{O}_{4} \mathrm{MNPs}-\mathrm{GQDs}$ particles reached $30 \mathrm{~nm}$.

In addition, the surface chemistry of $\mathrm{Fe}_{3} \mathrm{O}_{4}$ MNPs-GQDs was investigated using FTIR. The typical FT-IR spectra of magnetic nanoparticles are shown in Fig. 2. As can be seen the Fe-O band at $\mathrm{Fe}_{3} \mathrm{O}_{4}$ MNPs-GQDs $\left(611 \mathrm{~cm}^{-1}\right)$ shifted to a higher wavelength in comparison with $\mathrm{Fe}_{3} \mathrm{O}_{4}$ $\left(580 \mathrm{~cm}^{-1}\right)$, indicating the bonding of $\mathrm{Fe}_{3} \mathrm{O}_{4}$ to $\mathrm{C}-\mathrm{O}-\mathrm{H}$ groups on the GQDs surface. An absorption bond appeared at $3411 \mathrm{~cm}^{-1}$ corresponding to hydroxyl groups on $\mathrm{Fe}_{3} \mathrm{O}_{4}$ and the $\mathrm{Fe}_{3} \mathrm{O}_{4}$ MNPs-GQDs surface and a peak at $1618 \mathrm{~cm}^{-1}$ corresponded to the vibration of water molecules adsorbed on $\mathrm{Fe}_{3} \mathrm{O}_{4}$ and $\mathrm{Fe}_{3} \mathrm{O}_{4}$ MNPs-GQDs surfaces. A strong bond at $1605 \mathrm{~cm}^{-1}$ corresponded to the stretching frequencies of $\mathrm{C}-\mathrm{C}$ on the $\mathrm{Fe}_{3} \mathrm{O}_{4} \mathrm{MNPs}-\mathrm{GQDs}$ surface. Peaks at $908 \mathrm{~cm}^{-1}$ and $1065 \mathrm{~cm}^{-1}$ can be attributed to the stretching frequencies of $\mathrm{C}-\mathrm{C}$ on $\mathrm{Fe}_{3} \mathrm{O}_{4} \mathrm{MNPs}^{-}$ GQDs and the peaks at $1258 \mathrm{~cm}^{-1}$ and $1384 \mathrm{~cm}^{-1}$ corresponded to the $\mathrm{C}-\mathrm{O}$ stretching and $\mathrm{O}-\mathrm{H}$ bending vibrations. 


\subsection{Preparation of GQDs and $\mathrm{Fe}_{3} \mathrm{O}_{4}$ MNPs-GQDs modified GCE (GQDs-GCE and $\mathrm{Fe}_{3} \mathrm{O}_{4}$}

\section{MNPs-GQDs-GCE)}

GCE ( $2 \mathrm{~mm}$ in diameter) was polished to a mirror-like finish with 0.3 and $0.05 \mu \mathrm{m}$ alumina slurry and then thoroughly rinsed with double distilled water. Then it was successively sonicated in acetone and double distilled water and was allowed to dry at room temperature. Finally, $5 \mathrm{~mL}$ homogenous GQD and Mag-GQD films were electrodeposited onto GCE by cyclic voltammetry (CV) in the potential range from -1.0 to $1.0 \mathrm{~V}$ at a scan rate of $200 \mathrm{mV} \mathrm{s}^{-1}$ for 30 cycles (Fig. 3). When the cyclic potential scan reached 30 cycles, the peak currents hardly changed. The first positive scan, an oxidation peak (I) at $+0.51 \mathrm{~V}$ was observed, which is attributed to the oxidation of the $\mathrm{Fe}_{3} \mathrm{O}_{4}$ MNPs-GQDs. In the subsequent reversal scan, one reduction peaks (II) were observed at $-0.7 \mathrm{~V}$, which may be attributed to the reduction of species. In addition, it's found that, peak I was decreased cycle by cycle, and reflecting the continuous growth of the $\mathrm{Fe}_{3} \mathrm{O}_{4}$ MNPs-GQDs on the surface of GCE. These facts indicate that $\mathrm{Fe}_{3} \mathrm{O}_{4}$ MNPs-GQDs was successfully deposited on the surface of GCE by the electrochemical method.

After electrochemical deposition of $\mathrm{Fe}_{3} \mathrm{O}_{4}$ MNPs-GQDs on the GCE, the $\mathrm{Fe}_{3} \mathrm{O}_{4}$ MNPs-GQDs GCE was employed for taking SEM images for monitoring the distribution of $\mathrm{Fe}_{3} \mathrm{O}_{4}$ MNPs and morphology of the engineered electrode surface. The SEM images of the engineered electrode surface have been shown in Fig. 4 at different magnitudes. This Figure shows that magnetic nanoparticles were distributed into GQDs and confirmed attachment of $\mathrm{Fe}_{3} \mathrm{O}_{4}$ MNPs to the GQDs. Meanwhile the figure shows that some of $\mathrm{Fe}_{3} \mathrm{O}_{4}$ MNPs have been aggregated. The overall size of $\mathrm{Fe}_{3} \mathrm{O}_{4}$ MNPs was found to be less than $100 \mathrm{~nm}$. The $\mathrm{Fe}_{3} \mathrm{O}_{4}$ MNPs were well dispersed on the electrode surface. The effective surface area was $0.098,0.12$ and $0.289 \mathrm{~cm}^{2}$ for GCE, GQDs-GCE, and $\mathrm{Fe}_{3} \mathrm{O}_{4}$ MNPs-GQDs-GCE, respectively.

\section{Results and discussion}

\subsection{Electrochemical behavior}

Following a qualitative assessment prepared $\mathrm{Fe}_{3} \mathrm{O}_{4}$ MNPs-GQDs-GCE with GQDS-GCE; the electrochemical behavior of these sensors was investigated in further detail. The cyclic voltammograms of GCE, GQDs-GCE and $\mathrm{Fe}_{3} \mathrm{O}_{4}$ MNPs-GQDs-GCE were recorded between -1.0 and $1.0 \mathrm{~V}$ using the scan rate of $100 \mathrm{mVs}^{-1}$ in the $0.1 \mathrm{M}$ PBS $(\mathrm{pH}=7.4)$ and selected amino acids (L-Cysteine, L-Tyrosine, L-Glycine, and LPhenylalanine). Fig. 5 and 6 compares the cyclic voltammetric response of the $\mathrm{Fe}_{3} \mathrm{O}_{4}$ MNPs-GQDs-GCE with GQDs-GCE. The $\mathrm{Fe}_{3} \mathrm{O}_{4}$ MNPs-GQDs-GCE display well fined oxidation peaks for all four analytes.

As can be seen in Fig. 5A-D, on the bare GCE electrode no redox behavior was observed. On the other hand, as well as on the GQDs-GCE (Fig. 5, curve a) and $\mathrm{Fe}_{3} \mathrm{O}_{4}$ MNPs-GQDs-GCE (Fig. 6, curve b) one pair redox peaks was appeared at $0.13 \mathrm{~V} v s$. $\mathrm{Ag} / \mathrm{AgCl}$. The comparison of recorded CVs using GQDs-GCE and $\mathrm{Fe}_{3} \mathrm{O}_{4}$ MNPs-GQDs-GCE in the presence of selected L-Cysteine, LTyrosine, L-Aspartic Acid, and L-Phenylalanine (Fig. 6, curve b) shows a new anodic peak at $0.628,0.638,0.672,0.445 \mathrm{~V} v s . \mathrm{Ag} / \mathrm{AgCl}$ which attribute to the anodic oxidation of L-Cysteine, 
L-Tyrosine, L-Aspartic Acid, and L-Phenylalanine, respectively. This observation is also attributed to the high conductivity and inherent ability of $\mathrm{Fe}_{3} \mathrm{O}_{4}$ MNPs-GQDs. From the above two figures, it can be concluded that without catalytically agent $\left(\mathrm{Fe}_{3} \mathrm{O}_{4} \mathrm{MNPs}\right)$, bare GCE or GQDs-GCE cannot result in the successful electrooxidation of selected amino acid. When $\mathrm{Fe}_{3} \mathrm{O}_{4}$ MNPs containing catalyst agent is used to modify GQD, the differences in peak currents are obviously enlarged, suggesting that $\mathrm{Fe}_{3} \mathrm{O}_{4}$ MNPs-GQDs can provide an acceleration center to electron shuttling [40, 42, and 47]. These results show the anodic peak currents at the surface of $\mathrm{Fe}_{3} \mathrm{O}_{4}$ MNPs-GQDs-GCE are significantly enhanced. These results indicate that $\mathrm{Fe}_{3} \mathrm{O}_{4}$ MNPsGQDs film could accelerate the rate of electron transfer of selected amino acids and have good electrocatalytic activity for redox reaction of L-Cysteine, L-Tyrosine, L-Aspartic Acid, and LPhenylalanine [40-49]. Therefore, $\mathrm{Fe}_{3} \mathrm{O}_{4}$ MNPs-GQDs is a suitable mediator to shuttle electron between amino acid and working electrode, and facilitate electrochemical regeneration following electron exchange with amino acid. That might be related to the excellent properties of $\mathrm{Fe}_{3} \mathrm{O}_{4}$ MNPs-GQDs such as high specific surface area and electrical conductivity [40, 42, and 47]. Also, the recognition efficiency is further improved at the $\mathrm{Fe}_{3} \mathrm{O}_{4}$ MNPs-GQDs-GCE with a peak current ratio of 4.1 (Fig. 3D), it is no doubt that $\mathrm{Fe}_{3} \mathrm{O}_{4}$ MNPs play important roles in the improvement of catalytically activity of GQDs towards electrooxidation of amino acid. As a decisive catalytical component in the composite film, $\mathrm{Fe}_{3} \mathrm{O}_{4}$ MMNPs provides a catalytically platform for selective detection of amino acid meanwhile, GQDs can amplify the electrochemical signals produced during the electrochemical sensing process. In one word, the synergetic effect of GQDs and $\mathrm{Fe}_{3} \mathrm{O}_{4}$ MNPs leads to a successful and effective detection of amino acid.

So, $\mathrm{Fe}_{3} \mathrm{O}_{4}$ MNPs-GQDs could be substituted for other electrode modifiers. In addition, in the presence of Amino acid, it was observed that the anodic current and the associated anodic charge increased dramatically, whereas the cathodic current and the corresponding charge decreased. In the presence of Amino acid, the $\mathrm{I}_{\mathrm{pa}} / \mathrm{I}_{\mathrm{pc}}$ ratio was 78.0 ; in the absence of Amino acid, this ratio was decreased to 28.0. This result indicates that amino acid is oxidized by active $\mathrm{Fe}$ (III) moiety through a cyclic mediation redox process. Iron species are immobilized on the electrode surface, and the one with a higher valence oxidizes to Fe(III) via a chemical reaction followed by the generation of low valence iron (Fe(II) species). Along this line, the high-valence oxide is regenerated through the external electrical circuit. Accordingly, Amino acid is oxidized via an EC' mechanism. Finally, we noticed that the peak current values exhibited a linear dependence on the concentration of amino acid, suggesting the utility of the modified electrodes for analytical applications. Thus, it is likely that the electrogenerated Fe(III) species is the active moiety that efficiently speeds up the oxidation of Amino acid. Any increase in the concentration of Amino acid causes a proportional and nearly linear enhancement of the anodic wave.

The observed electrochemical behavior for $\mathrm{Fe}_{3} \mathrm{O}_{4}$ MNPs-GQDs -GCE in PBS $(\mathrm{pH}=7.4)$ could be attributed to the iron phosphate redox system. At first, $\mathrm{Fe}_{3} \mathrm{O}_{4}$ MNPs directly reduced at the electrode surface according to the following reaction:

$$
\mathrm{Fe}_{3} \mathrm{O}_{4}(\mathrm{~s})+2 \mathrm{e}^{-}+6 \mathrm{H}^{+}(\mathrm{aq}) \rightarrow 2 \mathrm{Fe}^{2+}(\mathrm{aq})+3 \mathrm{H}_{2} \mathrm{O}+\mathrm{FeO}(\mathrm{s})
$$

Then, $\mathrm{Fe}^{2+}$ ions produced could combine with phosphate ions in the buffer solution:

$$
\mathrm{Fe}^{2+}(\mathrm{aq})+\mathrm{HPO}_{4}{ }^{2-}(\mathrm{aq}) \rightarrow \mathrm{FePO}_{4}(\mathrm{~s})+\mathrm{e}^{-}+\mathrm{H}^{+}(\mathrm{aq})
$$


Here after, the solid $\mathrm{FePO}_{4}$ at the surface of electrode could be responsible for observed redox behavior. Therefore, the electrocatalytic activity of $\mathrm{Fe}_{3} \mathrm{O}_{4}$ MNPs-GQDs can be ascribed to the combination of the electron-acceptor ability of $\mathrm{Fe}_{3} \mathrm{O}_{4} \mathrm{MNPs}$ and confinement effects due to the attachment to the GQDs matrix. On the basis of the previous considerations, the electrocatalytic activity of $\mathrm{Fe}_{3} \mathrm{O}_{4}$ MNPs-GQDs must result from the superposition of the effect associated with more external MNPs units and that due to boundary-associated ones. On the other hand, since the catalytic effect associated with $\mathrm{Fe}_{3} \mathrm{O}_{4}$ MNPs consists essentially of an enhancement of the anodic peak for amino acid oxidation, the catalytic effect can tentatively be associated with a redox reaction in solution phase between $\mathrm{Fe}_{3} \mathrm{O}_{4}$ and any intermediate species resulting from the initial electron transfer of amino acid.

It is important to point out that, we have a negative approach in CVs of other amino acids (L-Serine, L- Arginine, L-valine, and L-Glycine) which were recorded and no response was observed which indicated no response of proposed sensor $\left(\mathrm{Fe}_{3} \mathrm{O}_{4} \mathrm{MNPs}-\mathrm{GQDs}-\right.$ GCE) towards detection of these amino acids (See Fig. 7).

Scan rate is one of parameters significantly affecting electrooxidation of various compounds. Also, useful information involving electrochemical mechanism usually can be acquired from the relationship between peak current and scan rate. Therefore, the electrochemical behaviors of selected amino acids at different scan rates were investigated on the surface of $\mathrm{Fe}_{3} \mathrm{O}_{4} \mathrm{MNPs}^{-}$ GQDs-GCE by CV. Fig. 8A presents typical CV of a $\mathrm{Fe}_{3} \mathrm{O}_{4} \mathrm{MNPs}^{-G Q D s-G C E}$ in $0.1 \mathrm{M}$ PBS $(\mathrm{pH}=7.4)$ at various potential sweep rates from $2-1000 \mathrm{mV} \mathrm{s}^{-1}$. The peak's currents are proportional to sweep rates in the range of $20-500 \mathrm{mV} \mathrm{s}^{-1}$, as shown in Fig. 7B, pointing to the electrochemical activity of the surface redox couple. From the slope of this lines and using:

$I_{p}=\left(\frac{n^{2} F^{2}}{4 R T}\right) v A \Gamma^{*}$

where $\Gamma^{*}$ is the surface coverage of the redox species and $v$ being the potential sweep rate $[53,54]$ and taking average of both cathodic and anodic results, $\Gamma^{*}$ values of around $8.5 \times 10^{-10} \mathrm{~mol} \mathrm{~cm}^{-2}$ have been derived.

Fig. 9 illustrates cyclic voltammograms of L-Cys, L-Tyr, L-Asp, and L-Phe using the $\mathrm{Fe}_{3} \mathrm{O}_{4}$ MNPs-GQDs-GCE recorded at different potential sweep rates. According to Fig. 9, Fig. 10 A and $\mathrm{B}$ indicates anodic peak currents increased linearly with the square root of the potential sweep rate $\left(50-500 \mathrm{mVs}^{-1}\right)$ for L-Cys, which indicates a mass transfer-controlling process of oxidation via diffusion. In addition the value of the electron-transfer coefficient for the reaction can be obtained from the following equation: [55]

$E p=\left(\frac{R T}{2 \alpha F}\right) \ln v+c o n s \tan t$

This is valid for a totally irreversible diffusion-controlled process. Using the dependency of anodic peak potential on the Neperian logarithm of the potential sweep rate (Fig. 10C), the value of the electron-transfer coefficient was obtained as 0.6. On the basis of the slopes of the linear dependency of the anodic peak currents on the square root of the potential sweep rates, and the Randles-Sevcik equation: [56] 


$$
I=\left(2.99 \times 10^{5}\right) \alpha^{1 / 2} n^{3 / 2} A C^{*} D^{1 / 2} v^{1 / 2}
$$

where $I_{p}$ is the peak current, $A$ is the electrode surface area, $D$ is the diffusion coefficient, and $C^{*}$ is the bulk concentration of L-Cys, the diffusion coefficient (D) for L-Cys was calculated to be $0.34 \times 10^{-5} \mathrm{~cm}^{2} \mathrm{~s}^{-1}$. Also, plotting the current function (peak current divided by the square root of the potential sweep rate) against the square root of the potential sweep rate revealed negative slope confirming the electrocatalytic nature of the process. These results indicated that prepared film could accelerate the rate of electron transfer of L-Cys and have good electrocatalytic activity for redox reaction of L-Cys. Similar results were obtained for L-Tyr, L-Asp, and L-Phe which the results were summarized on Table 1. Also oxidation mechanisms for the studied amino acids are presented in scheme 2 .

For further confirmation, chronoamperometery was used for investigation the electrochemical behavior of selected amino acids using $\mathrm{Fe}_{3} \mathrm{O}_{4}$ MNPs-GQDs (Fig. 11). Single steps chronoamperograms were recorded by setting the working electrode potentials to desired values and were used to measure the catalytic rate constant on the modified surface over a concentration range of $0.05-0.1 \mathrm{M}$. The plot of net current versus $\mathrm{t}^{-1 / 2}$ which has been obtained by removing the background current by the point-by-point subtraction method gives a straight line. This indicates that the transient current must be controlled by a diffusion process. By using the slopes of these lines; we can obtain the diffusion coefficients of the selected amino acids according to the Cottrell equation: [57]

$$
I=n F A D^{1 / 2} C^{*} \pi^{-1 / 2} t^{-1 / 2}
$$

where $\mathrm{D}$ is the diffusion coefficient, and $\mathrm{C}^{*}$ is the bulk concentration. The mean value of the diffusion coefficients for L-Tyr, L-Asp, and L-Phe were cited on the Table 1

\subsection{Analytical application}

The calibration curve for amino acids in PBS $(\mathrm{pH}=7.4)$ was obtained by DPV. Fig. 12 shows typical DPV curves for different concentrations of L-Cys, L-Tyr, L-Asp, and L-Phe in PBS using $\mathrm{Fe}_{3} \mathrm{O}_{4}$ MNPs-GQDs-GCE. The dependency between peak current and concentration was rectilinear for selected amino acids. The lower limits of quantitation (LLOQ) were found to be in sub-micromolar for oxidation peaks of selected amino acids. The results were summarized in Table 1.

\subsection{Reproducibility and stability}

Another advantage of the proposed modified electrode was that the resulting modified electrode showed good long term stability. Stability of the proposed electrode was tested by measuring the decrease in voltammetric current during repetitive DPV measurements of amino acids with $\mathrm{Fe}_{3} \mathrm{O}_{4}$ MNPs-GQDs-GCE stored in solution or air. For example, this electrode, within $24 \mathrm{~h}$, is used for the determination of $1 \mathrm{mM}$ amino acids in buffer solutions. Obtained results show that this electrode has remarkable stability without significant change in the voltammetric currents. When the electrode was stored in the atmosphere, the current response remained almost unchanged for about 20 days. RSD of repeated peak currents was $(6.1 \%)$. The high stability of 
the $\mathrm{Fe}_{3} \mathrm{O}_{4}$ MNPs-GQDs-GCE could be related to the strong affinity of $\mathrm{Fe}_{3} \mathrm{O}_{4}$ MNPs for GQDs and the low solubility of the $\mathrm{Fe}_{3} \mathrm{O}_{4}$ MNPs-GQDs-GCE in water. To check the inter-electrode reproducibility of the modified electrode, four modified electrodes were tested simultaneously by recording DPVs in buffer solution, containing $1 \mathrm{mM}$ of amino acids. The relative standard deviation was $4.82 \%$. Therefore, $1 \mathrm{mM}$ imparts a suitable stability onto DPVs measurements of amino acids.

\section{Conclusions}

In summary, $\mathrm{Fe}_{3} \mathrm{O}_{4}$ MNPs-GQDs was electrodeposited on GCE by cyclic voltammetry (CV) in the potential range from -1.0 to $1.0 \mathrm{~V}$ and used for detection of some amino acid at physiological $\mathrm{pH}$. The $\mathrm{Fe}_{3} \mathrm{O}_{4}$ MNPs-GQDs-GCE showed better performance for the electrochemical oxidation of amino acid, when compared with bare GCE and GQD-GCE. More importantly, the proposed nano-sensor was used for determination of selected amino acids at physiological $\mathrm{pH}$, without the necessity for sample pre-treatment or any time-consuming extraction or evaporation steps prior to the analysis, with satisfactory analytical results. The analytical performance of modified electrode indicates that it can be used as sensitive amperometric detector for detection of amino acids when coupled with flow system. Also due to remarkable electrocatalytic properties of $\mathrm{Fe}_{3} \mathrm{O}_{4}$ MNPs-GQDs-GCE, prepared sensor can be used for determination of some other amino acids which are necessary for interference study.

\section{Acknowledgments}

We gratefully acknowledge the partial financial support by the Drug Applied Research Center Research Center, Tabriz University of Medical Sciences, Higher Education Institute of RabRashid, Nano Technology Research Center, and Faculty of Chemistry, Urmia University, and also the Iran National Science Foundation (INSF) for supporting this research. 


\section{References}

[1] S. Hanjun, W. Li, W. Weili, Q. Xiaogang. Recent advances in graphene quantum dots for sensing. Mater Today 16 (2013) 433-442

[2] H. Guoqiang, S. Yang, L. Ke, W. Andrew, C. Sophie, C. Shaowei Oxygen reduction catalyzed by Platinum Nanoparticles Supported on Graphene Quantum Dots. ACS Catal. 3 (2013) 831-838

[3] L .Wen-Wen, F. Ya-Qiang, Y.Xing-Bin, Ch. Jiang-Tao, X.Qun-Ji. Superior MicroSupercapacitors Based on Graphene Quantum Dots. Adv. Funct Mater 23 (2013) 4111-4122

[4] L.Wen-wen, Y. Xingbin, Ch.Jiangtao, F. Yaqiang, X. Qunji. Novel and high- performance asymmetric micro-supercapacitors based on graphene quantum dots and polyaniline nanofibers. Nanoscale 5 (2013) 6053-6062

[5] G. Vinay, Ch. Neeraj, S. Ritu, Sh. Gauri Datt, B. Ramil, Ch. Suresh. Luminscent Graphene Quantum Dots for Organic Photovoltaic Devices. J. Am. Chem. Soc. 133 (2011) 99609963

[6] Z. Jing, Ch. Guifang, Z. Li, L.Genxi. Graphene quantum dots-based platform for the fabrication of electrochemical biosensors. Electrochem. Commun. 13 (2011) 31-33

[7] H. Razmi, R. Mohammad-Rezaei. Graphene quantum dots as a new substrate for immobilization and direct electrochemistry of glucose oxidase: application to sensitive glucose determination. Biosens. Bioelectron. 41 (2013) 498-504.

[8] Sh. Dhanraj, P. Vijamohanank. Electrochemical Resolution of Multiple Redox Events for Graphene Quantum Dots. Angew. Chem. Int. Ed 52 (2013) 2482-2485

[9] M. Roushani, Z. Abdi. Novel electrochemical sensor based on graphene quantum dots/riboflavin nanocomposite for the detection of persulfate. Sensors Actuators B: Chemical 201 (2014) 503-510

[10] B. Mitchell, B.Siobhan, N. Thomas. Graphene Quantum Dots. Part. Part. Syst. Charact 31 (2014) 415-428

[11] L. Lingling, W. Gehui, Y. Guohai, P. Juan, Z. Jianwei, Z. Jun-Jie. A high impact peer reviewed journal publishing experimental and theoretical work across the breadth of nanoscience and nanotechnology. Nanoscale 5 (2013) 4015-4039

[12] Q. Zhi-bei, Z. Xinguang, G. Li, L. Renmin, S. Dandan, Y. Dajun, Sh. Guoyue. Boronic acid functionalized graphene quantum dots as a fluorescent probe for selective and sensitive glucose determination in microdialysate. Chem. Commun 49 (2013) 9830-9832

[13] W. Baojuan, Z.Shujuan , Ch.Luyang, Z.Yongjun. Fluorescent graphene quantum dot nanoprobes for the sensitive and selective detection of mercury ions. Acta Part A 131 (2014) $384-387$ 
[14] P. Dengyu, Z. Jingchun, L. Zhen, W. Minghong. Hydrothermal Route for Cutting Graphene Sheets into Blue-Luminescent Graphene Quantum Dots. Adv. Mater. 22 (2010) 734-738

[15] W. Xiaochen, Z. Yan, H. Ting, W. Haixia, G. Shouwu , Z. Jingyan. Composite of graphene quantum dots and $\mathrm{Fe}_{3} \mathrm{O}_{4}$ nanoparticles: peroxidase activity and application in phenolic compound remova. RSC Adv 4 (2014) 3299-3305

[16] R. Mohammad-Rezaei, H. Razmi, V. Abdollahi, AA. Matin. Preparation and characterization of $\mathrm{Fe}_{3} \mathrm{O}_{4}$ /graphene quantum dots nanocomposite as an efficient adsorbent in magnetic solid phase extraction: application to determination of bisphenol $\mathrm{A}$ in water samples. Anal. Methods 6 (2014) 8413-8419

[17] M. Stanford, H. William. Stein. Chromatographic determination of amino acids by the use of automatic recording equipment. Methods Enzym 6 (1963) 819-831

[18] E. Harold. Spectroscopic Determination of Tryptophan and Tyrosine in Proteins. Biochemistry 6 (1967) 1948-1954

[19] J.L. Young, M. Yamamoto. A Mixed Lithium-Sodium Gradient Buffer System for SingleColumn Amino Acid Chromatography J. Chromatogr. 78 (1973) ,349-355.

[20] Y. K.Umit, A. Thomas, A. Izydor, F. Jay, C. John, P. Raymond, Sh. Daniel. amino acid analysis of phospho-peptides:abrf-93AAA.in Techniques in Protein Chemistry (1994) 185

[21] T. Margaret. Amino Acid Analysis. Methods Mol. Biol. 159 (2000) 1-7

[22] G. Sarwar, H.G. Botting. Evaluation of liquid chromatographic analysis of nutritionally important amino acids in food and physiological samples. Chromatograph 615 (1993) 1-22

[23] C.Bruton. Evaluation of liquid chromatographic analysis of nutritionally important amino acids in food and physiological samples. Clin. Lab. Hematology 22(1986) 123-125

[24] P. Fürst, L. Pollack, T.A. Graser, H. Godel, P. Stehle. Appraisal of four pre-column derivatization methods for the high-performance liquid chromatographic determination of free amino acids in biological materials. Chromatogr. 499 (1990) 557-569

[25] S.Maurizio, B. Daniela De, B. Donatella, B.Francesco. Automated amino acid analysis using precolumn derivatization with dansylchloride reversed-phase high-performance liquid chromatography. J. Chromatogr 504 (1990) 129-138

[26] H.Paul, Sh.David, G.Lisa, K. Jeffrey, R.John . Applications of automated amino acid analysis using 9-fluorenylmethyl chloroformate. J. Chromatogr. 588 (1991) 107-114

[27] K. Ou, R.M. Wilkins, X.J. Yan, A.A. Gooley, Y. Fung, D. Sheumack, L.K. Williams. Improved high-performance liquid chromatography of amino acids derivatised with 9fluorenylmethyl chloroformate. J. Chromatogr 723 (1996) 219 -225

[28] A.Gratsfeld-Huesgen Hewlett Packard Technical Note 12 (1998) 5966-3110E 
[29] R. Gatti, M.G. Gioia, P. Andreatta, G. Pentassuglia. HPLC-fluorescence determination of amino acids in pharmaceuticals after pre-column derivatization with phanquinone. $J$. Pharmaceut. Biomed. Anal 35 (2004) 339-348

[30] B. Lourdes, A. Amparo, F. Rosaura. Application of the 6-aminoquinolyl-Nhydroxysccinimidyl carbamate (AQC) reagent to the RP-HPLC determination of amino acids in infant foods. J. Chromatogr B 831 (2006) 176-183

[31] L. Xilong, R. Rezaei, L.Peng, W. Guoyao. Composition of amino acids in feed ingredients for animal diets. Amino acids 40 (2011) 1159-1168

[32] P. Ana, M. González, B. J. Alfonso Gómez, M. Carlos Cordón, G.Rafael J, S. José Sánchez. HPLC-fluorimetric method for analysis of amino acids in products of the hive (honey and beepollen). Food Chem. 95 (2006) 148-156

[33] R. Hanczkó, A. Jámbor, A. Perl, I. Molnár-Perl.Advances in the o-phthalaldehyde derivatizations: Comeback to the o-phthalaldehyde-ethanethiol reagent. J. Chromatogr. A 1163 (2007) 25-42

[34] B. Wathelet . Nutritional analyses for proteins and amino acids in beans (Phaseolus sp). Biotechnol. Agron. Soc. Environ. 3 (1999) 197-200

[35] D .C. Turnell , J .D .Cooper . Rapid assay for amino acids in serum or urine by pre-column derivatization and reversed-phase liquid chromatography. Clin. Chem 28 (1982) 527-531

[36] E.Stefán. Selective determination of secondary amino acids using precolumn derivatization with 9-fluorenylmethylchloroformate and reversed-phase high-performance liquid chromatography. J. Chromatogr 348 (1985) 213-220

[37] J. Ozols. Amino acid analysis. Methods Enzymol. 182 (1990) 587-601.

[38] W.J. Henderson, D. R. Ricker, A.B. Bidlingmeyer, C. Woodward. Agilent Technical Note (2000) 5980-1193E,

[39] G. Vural, S. Arda, M. Burçe Ataç. Rapid determination of amino acids in foods by hydrophilic interaction liquid chromatography coupled to high-resolution mass spectrometry. Anal. Bioanal. Chem 403 (2012) 2915-2922

[40] M. Hasanzadeh, N. Shadjou, E. Omidini . Mesoporous silica (MCM-41)-Fe ${ }_{2} \mathrm{O}_{3}$ as a novel magnetic nanosensor for determination of trace amounts of amino acids. Colloids Surf. B: Biointerfaces 108 (2013) 52-59

[41] M. Hasanzadeh, N. Shadjou, Ch. Sue-Tsong, P. Sheikhzadeh . MCM-41-NH $\mathrm{NH}_{2}$ an advanced nanocatalyst for electrooxidation and determination of amino acids. Catal. Commun 19 (2012) 21-27

[42] L. Saghatforoush, M. Hasanzadeh, N. Shadjou, B. Khalilzadeh . Deposition of new thiacontaining schiff-base iron (III) complexes onto carbon nanotube-modified glassy carbon electrodes as a biosensor for electrooxidation and determination of amino acids. Electrochim. Acta 56 (2011) 1051-1061 
[43] M. Hasanzadeh, G. Karim-Nezhad, N. Shadjou, M. Hajjizadeh, B. Khalilzadeh, L.Saghatforousha, M.H.Abnosid, A. Babaeic, S.Ershade. Cobalt hydroxide nanoparticles modified glassy carbon electrode as a biosensor for electrooxidation and determination of some amino acids. Anal. Biochem 389 (2009) 130-137

[44] E. Omidinia, N. Shadjou, M. Hasanzadeh. Aptamer-based Biosensor for Detection of Phenylalanine at Physiological Ph. Appl. Biochem. Biotechnol 172 (2014) 2070-2080

[45] E. Omidinia, N. Shadjou, M. Hasanzadeh. Immobilization of phenylalanine-dehydrogenase on nano-sized polytaurine: A new platform for application of nano-polymeric materials on enzymatic biosensing technology. Mater. Sci. Eng 42 (2014) 368-373

[46] E. Omidinia, N. Shadjou, M. Hasanzadeh. Electrochemical Nanobiosensing of Phenylalanine Using Phenylalanine Dehydrogenase Incorporated on Amino-Functionalized Mobile Crystalline Material-41. Sens. J. IEEE 14 (2014) 1081-1088

[47] E. Omidinia, N. Shadjou, M. Hasanzadeh. $\left(\mathrm{Fe}_{3} \mathrm{O}_{4}\right)$-graphene oxide as a novel magnetic nanomaterial for non-enzymatic determination of phenylalanine. Mater. Sci. Eng. C 33 (2013) 4624-4632

[48] E. Omidinia, A. Khanehzar, N. Shadjou, H. Shahbaz Mohamadi, S. Hojati Emami, M. Hasanzadeh. Covalent Immobilization of Phenylalanine Dehydrogenase on GlutaraldehydeModified Poly (3,4-ethylenedioxy) Thiophene: Poly(styrenesulfonate)/ Polyvinyl Alcohol Conducting Polymer Composite Films for Electrochemical Detection of Lphenylalanine. Anal. Bioanal. Electrochem 5 (2013) 597-608

[49] B. Massoumi, S. Fathalipour, A. Massoudi, M. Hassanzadeh, A.A. Entezami. $\mathrm{Ag} /$ polyaniline nanocomposites: Synthesize, characterization, and application to the detection of dopamine and tyrosine. J. Appl. Polymer Sci 130 (2013) 2780-2789.

[50] S.M. MacDonald, S.G. Roscoe. Electrochemical oxidation reactions of tyrosine, tryptophan and related dipeptides. Electrochim. Acta 42 (1997) 1189-1200

[51] M. Daniel, G, W. Ian, R .Sharon G. Surface electrochemistry of the oxidation reactions of $\alpha$ and $\beta$-alanine at a platinum electrode. Bioelectrochem. Bioenerg. 25 (1991) 269-284

[52] F.Ying-Sing, M.Song-Ying. Determination of Amino Acids and Proteins by Dual-Electrode Detection in a Flow System. Anal. Chem 67 (1995) 1121-1124

[53] L.Ai-Lin, Z. Shao-Bo, Ch.Wei, L. Xin-Hua, X. Xing-Hua. Simultaneous voltammetric determination of norepinephrine, ascorbic acid and uric acid on polycalconcarboxylic acid modified glassy carbon electrode. Biosens. Bioelectron. 23 (2008) 1488-1495

[54] Sh. Fengjun, Z. Lin, Kh. A. Mahmoud, H. Sabahudin, L.Yali, M. Humphrey, G.Jeremy, L.John. Selective Nanomolar Detection of Dopamine Using a Boron-Doped Diamond Electrode Modified with an Electropolymerized Sulfobutylether- $\beta$-cyclodextrin-Doped Poly(Nacetyltyramine) and Polypyrrole Composite Film. Anal. Chem 81 (2009) 4089-4098

[55] L. Xiuhui, L. Li, Z. Xueping, L. Xiaoquan. Electrochemical behavior of rutin on a multiwalled carbon nanotube and ionic liquid composite film modified electrode. Colloids Surf. B Biointefaces 81 (2010) 344-349

[56] R. S. Nicholson, Sh. Irving. Theory of Stationary Electrode Polarography. Single Scan and Cyclic Methods Applied to Reversible, Irreversible, and Kinetic Systems. Anal. Chem. 36 (1964) 706-723

[57] Bard.J.A, Faulkner.R.L, Electrochemical Methods, Wiley, New York( 2001) 503-504. 
Table 1: Kinetic and analytical parameters of selected amino acids oxidation using $\mathrm{Fe}_{3} \mathrm{O}_{4}$ MNPs-GQDs-GCE

\begin{tabular}{|c|c|c|c|c|}
\hline Kinetic and analytical parameters & L-Cys & L-Tyr & L-Asp & L-Phe \\
\hline electron-transfer coefficient $(\alpha)$ & 0.60 & 0.55 & 0.32 & 0.61 \\
\hline diffusion coefficient (D)/ $\mathrm{cm}^{2} \mathrm{~s}^{-1}$ using CV & $0.34 \times 10^{-5}$ & $0.67 \times 10^{-5}$ & $0.12 \times 10^{-5}$ & $0.49 \times 10^{-5}$ \\
\hline diffusion coefficient (D)/ $\mathrm{cm}^{2} \mathrm{~s}^{-1}$ using CHA & $0.28 \times 10^{-5}$ & $0.44 \times 10^{-5}$ & $0.90 \times 10^{-5}$ & $0.11 \times 10^{-5}$ \\
\hline Linear rang $/ \mu \mathrm{M}$ & $0.01-100$ & $0.09-230$ & $1-50$ & $0.5-650$ \\
\hline $\mathrm{LLOQ} / \mu \mathrm{M}$ & 0.01 & 0.09 & 1 & 0.5 \\
\hline
\end{tabular}




\section{Figure Captions:}

Fig. 1: TEM, AFM images, and schematic representations structure of the GQDs $(A, B, C)$ and $\mathrm{Fe}_{3} \mathrm{O}_{4}$ MNPs-GQDs (D, E, F), respectively.

Fig. 2: FT-IR spectra of $\mathrm{Fe}_{3} \mathrm{O}_{4}$ MNPs and $\mathrm{Fe}_{3} \mathrm{O}_{4}$ MNPs-GQDs

Fig. 3: $\mathrm{CVs}$ for $5 \mathrm{~mL}$ of $\mathrm{Fe}_{3} \mathrm{O}_{4} \mathrm{MNP}-\mathrm{GQD}$ using a $\mathrm{GC}$ electrode scanned continuously at 200 $\mathrm{mVs}^{-1}$ between -1 to $+1 \mathrm{~V}$. Number of scan is 30 .

Fig. 4: SEM images of $\mathrm{Fe}_{3} \mathrm{O}_{4}$ MNP-GQDs modified GC electrode.

Fig. 5: CVs of GCE in the presence of $5 \mathrm{ml}$ PBS $(0.1 \mathrm{M}, \mathrm{pH}=7.4)+(0.004 \mathrm{~g} / \mathrm{ml})$ of amino acids. Scan rate is $100 \mathrm{mVs}^{-1}$.

Fig. 6: CVs of GQD-GCE (curve a) and $\mathrm{Fe}_{3} \mathrm{O}_{4}$ MNPs-GQDs-GCE (curve b) in the presence of 5 $\mathrm{ml}$ PBS $(0.1 \mathrm{M}, \mathrm{pH}=7.4)+(0.004 \mathrm{~g} / \mathrm{ml})$ of amino acids. Scan rate is $100 \mathrm{mVs}^{-1}$.

Fig. 7: $\mathrm{CVs}$ of $\mathrm{Fe}_{3} \mathrm{O}_{4}$ MNPs-GQDs-GCE in the presence of $5 \mathrm{ml} \mathrm{PBS}(0.1 \mathrm{M}, \mathrm{pH}=7.4)+(0.004$ $\mathrm{g} / \mathrm{ml}$ ) of other amino acids (L-Val, L-Ser, L-Arg, and L.Gly). Scan rate is $100 \mathrm{mVs}^{-1}$.

Fig. 8: A) CVs of a $\mathrm{Fe}_{3} \mathrm{O}_{4}$ MNPs-GQDs-GCE in $0.1 \mathrm{M}$ PBS in various potential sweep rates (from inner to outer): 2, 5, 10, 20, 30, 40, 50, 60, 70, 90, 100, 150, 200, 250, 300, 350, 400, 450, 50, 600, 700, 800, 900, and $1000 \mathrm{mVs}^{-1}$, respectively. B) Dependence of anodic/cathodic peak currents during the forward and reveres sweep $v s$. potential sweep rate.

Fig. 9: A) $\mathrm{CVs}$ of a $\mathrm{Fe}_{3} \mathrm{O}_{4}$ MNPs-GQDs-GCE in the presence of $0.004 \mathrm{~g} / \mathrm{ml}$ of [A) L-Cys, B) LTyr C) L-Asp, and D) L-phe]+0.1M PBS ( $\mathrm{pH}=7.4)$ in various potential sweep rates (from inner to outer): $2,5,10,20,30,40,50,60,70,90,100,150,200,250,300,350,400,450,50,600$, $700,800,900$, and $1000 \mathrm{mV} \mathrm{s}^{-1}$, respectively.

Fig. 10: A) Dependence of anodic/cathodic peak currents of $0.005 \mathrm{~g}$ of L-Cys during the forward and reveres sweep vs. potential sweep rate. B) Dependence of anodic/cathodic peak currents of $0.005 \mathrm{~g}$ of L-Cys during the square roots of forward and reveres sweep vs. potential sweep rate. C) Dependence of the peak potential on $L n v$ for the oxidation of L-Cys at $\mathrm{Fe}_{3} \mathrm{O}_{4}$ MNPs-GQDsGCE. D) Current function $v s . v^{0.5}$ for $0.1 \mathrm{M}$ PBS containing $0.005 \mathrm{~g}$ of L-Cys.

Fig. 11: Single step chronoamperograms of the $\mathrm{Fe}_{3} \mathrm{O}_{4}$ MNPs-GQDs-GCE in different concentrations of [A) L-Cys, B) L-Tyr C) L-Asp, and D) L-phe]: (0.1, 0.2, 0.25, 0.3, 0.33, 0.5, 0.66, 1, 1.33, 2, and $4 \mathrm{mM}$ ), respectively. Supporting electrolyte: $0.1 \mathrm{M}$; PBS (pH = 7.4); scan rate: $20 \mathrm{mV} \mathrm{s}^{-1}$. Potential step for L-Cys, L-Tyr, L-Asp, and L-Phe were 0.61, 0.68, 0.14, and $0.19 \mathrm{~V}$, respectively. B) Dependency of transient current on $\mathrm{t}^{-0.5}$.

Fig. 12: DPVs obtained for determination of [A) L-Cys, B) L-Tyr C) L-Asp, and D) L-phe] in $0.1 \mathrm{M}$ PBS, , respectively. A) L-Cys concentrations are as: 0.06, 0.07, 0.08, 0.1, 0.12, 0.14, 0.16, 0.18 , and 0.2. B) L-Tyr concentrations are as: 0.01, 0.02, 0.03, 0.04, 0.05, 0.07, 0.08, 0.09, and 0.1 . C) L-Asp concentrations are as: $0.2,0.4,0.7,1,5,10,20,50$, and 70. D) L-Phe concentrations are as: $0.2,0.4,0.5,0.8,1,2,5$, and 10 .

Scheme 1: Schematic setup for the synthesis of GQD and $\mathrm{Fe}_{3} \mathrm{O}_{4} \mathrm{MNPs}-\mathrm{GQDs}$

Scheme 2: A provisional mechanism for the electrooxidation of [A) L-Cys, B) L-Tyr, C) L-Asp, and D) L-phe] on $\mathrm{Fe}_{3} \mathrm{O}_{4}$ MNPs-GQDs-GCE. 

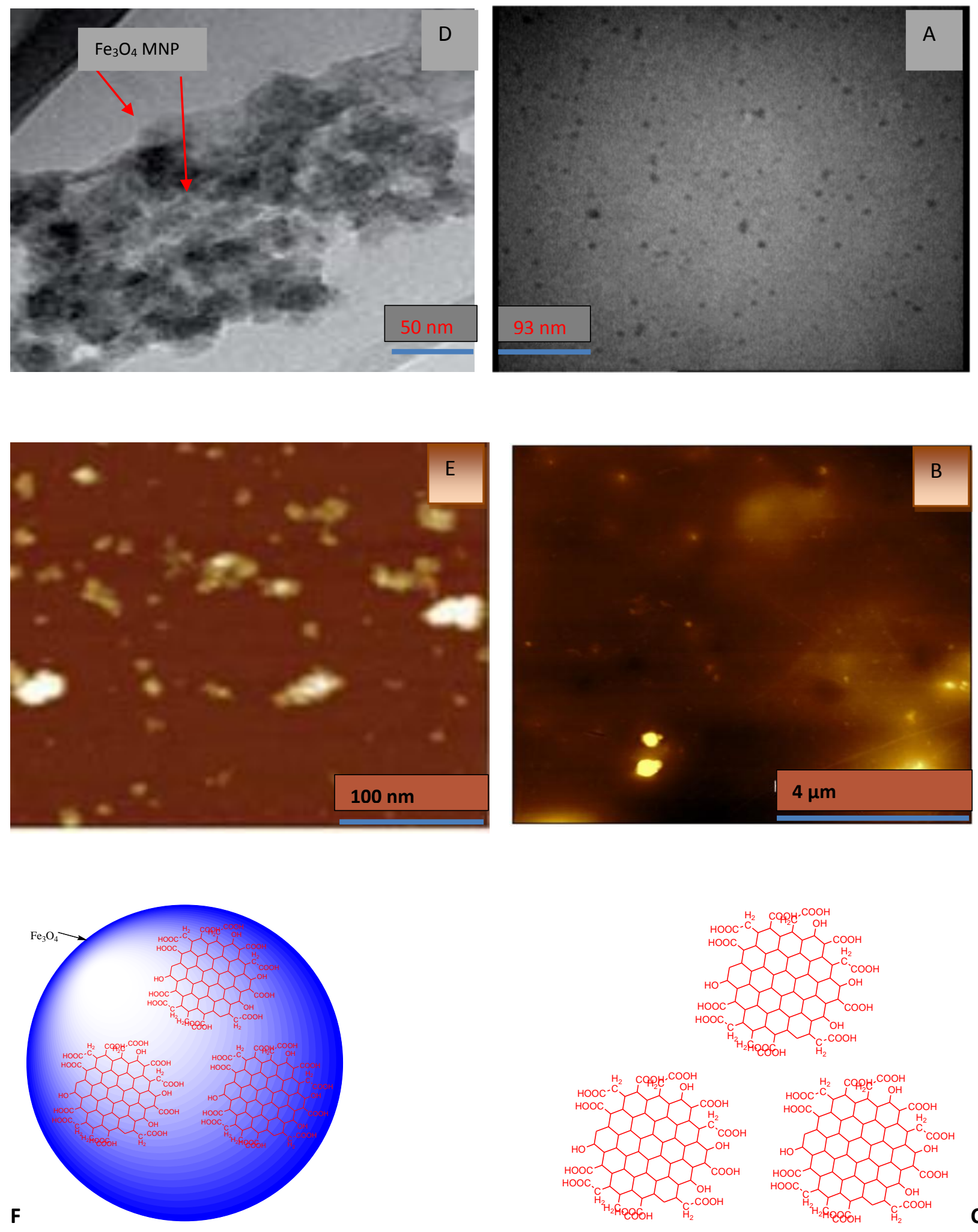

Fig. 1 


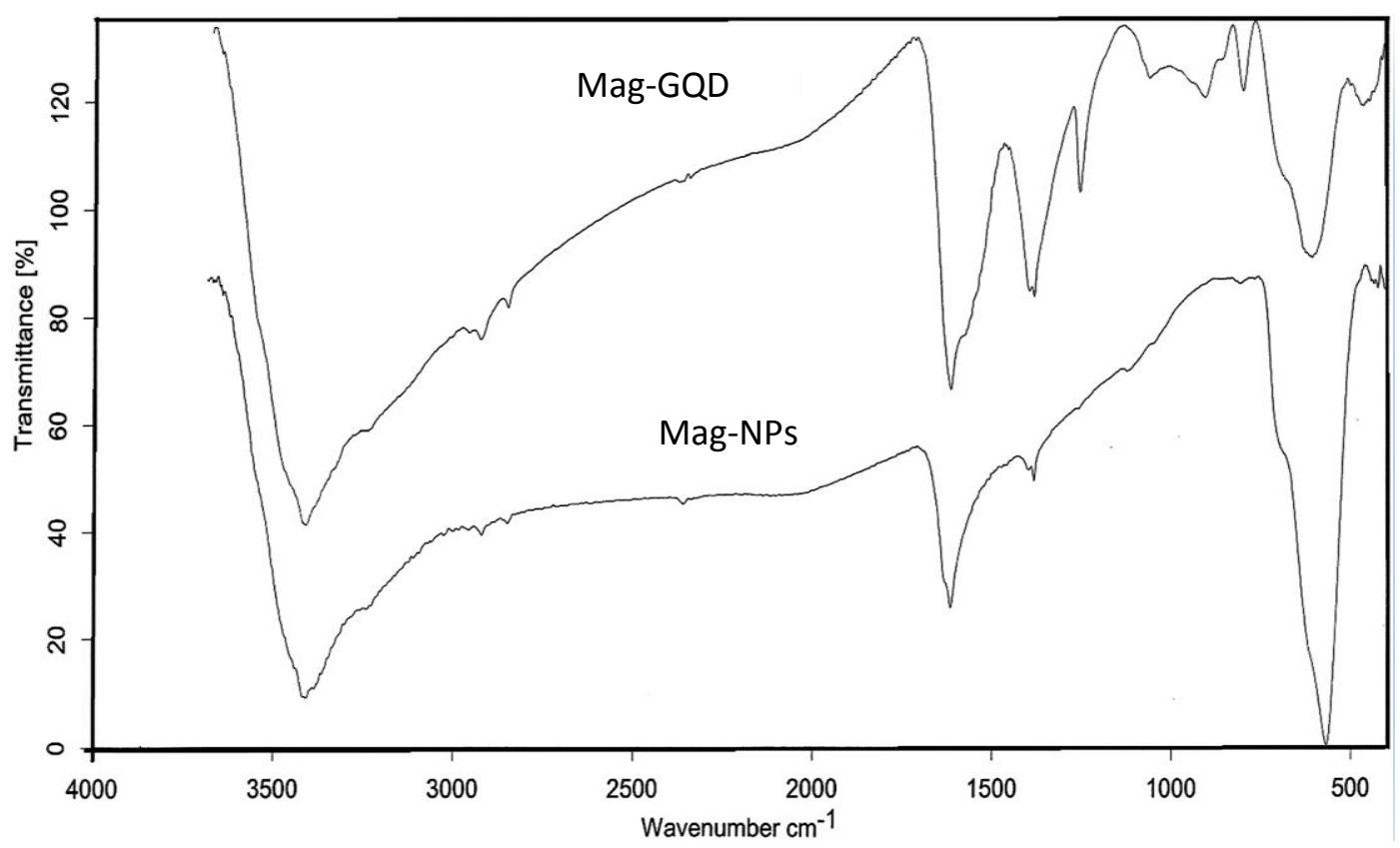

Fig. 2 


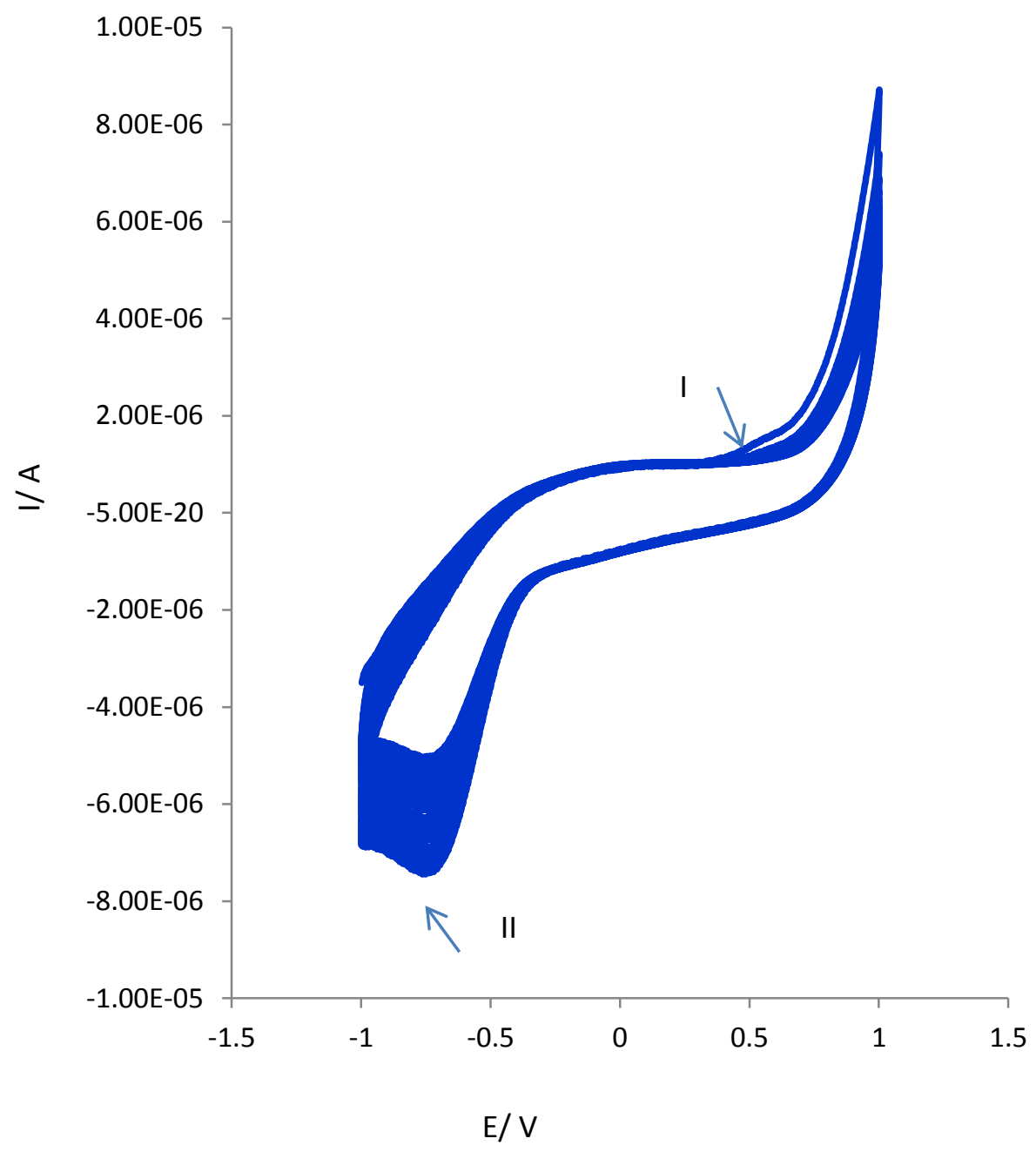

Fig. 3 


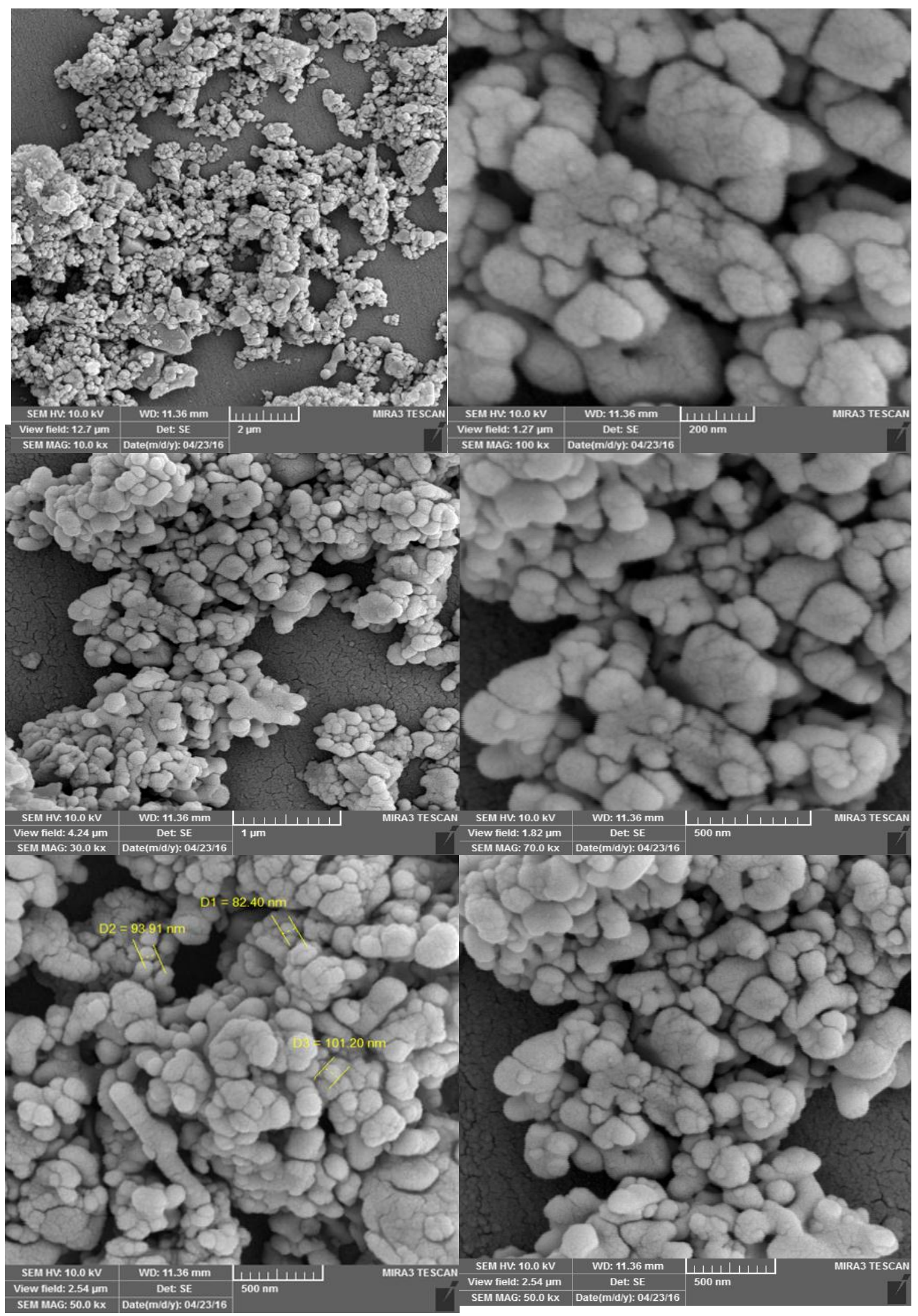




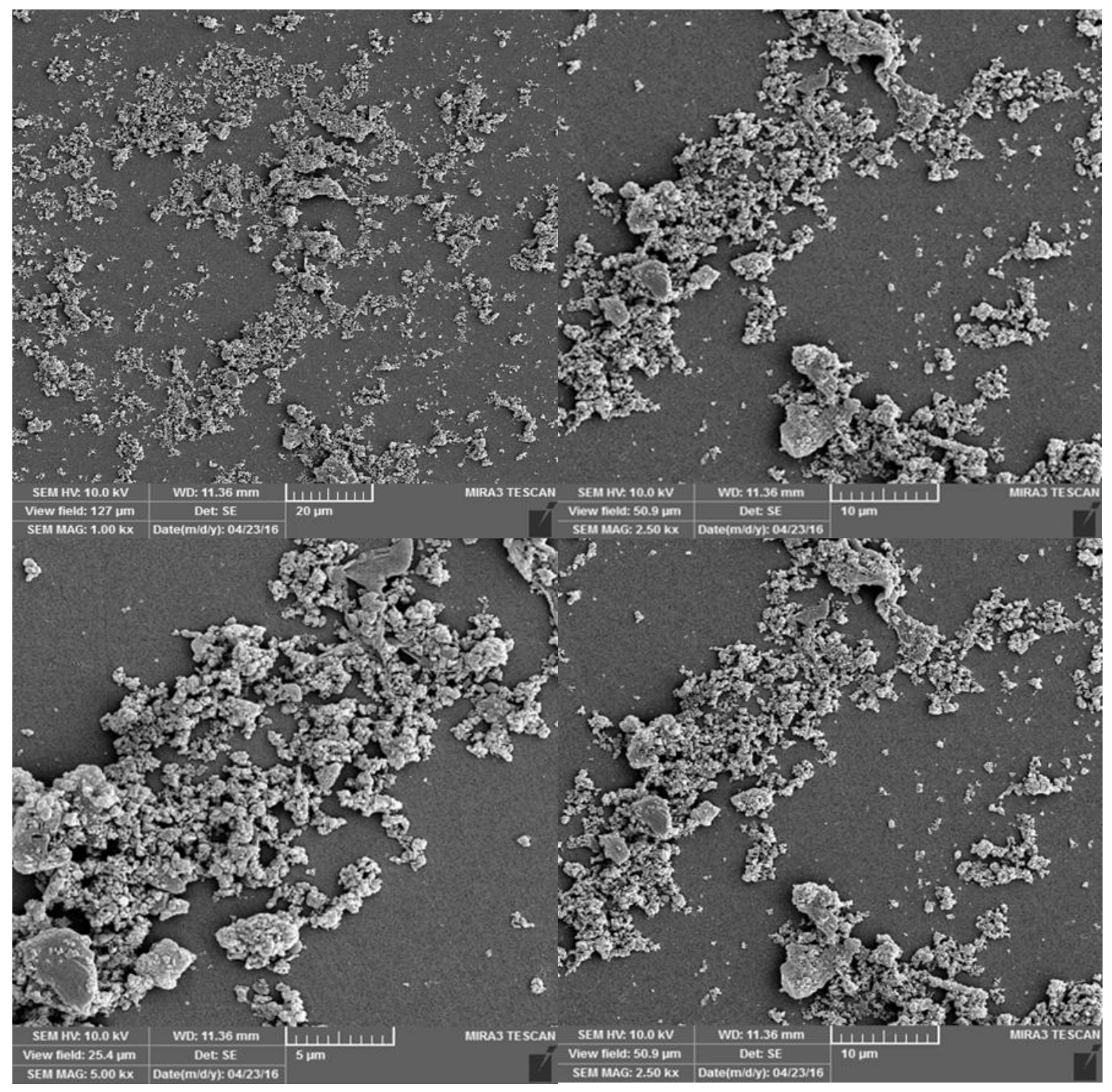

Fig. 4 

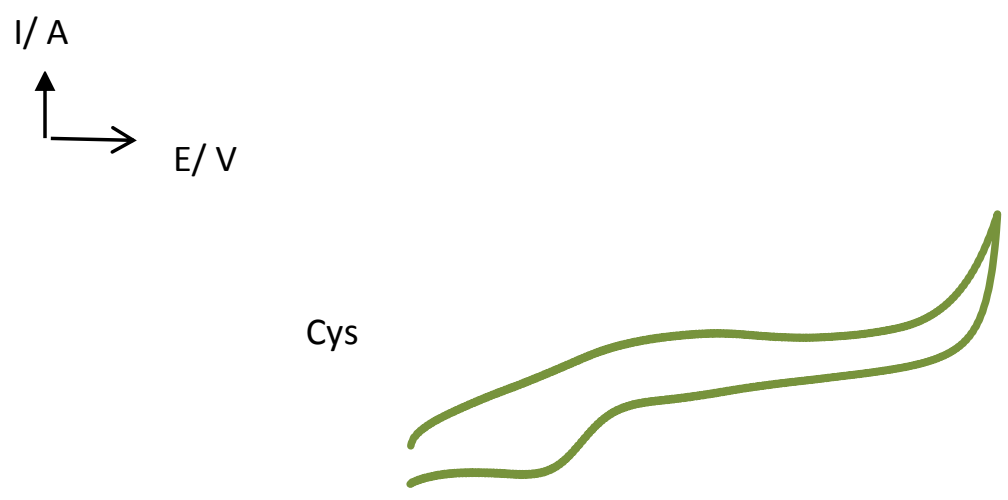

Tyr

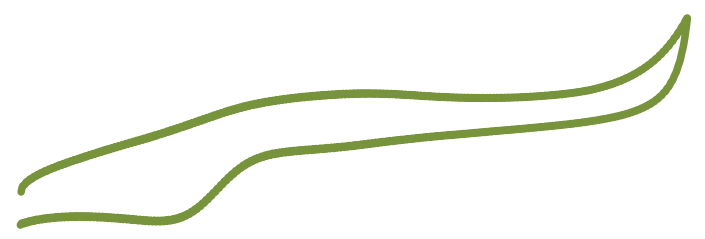

$5 \mu \mathrm{A}$
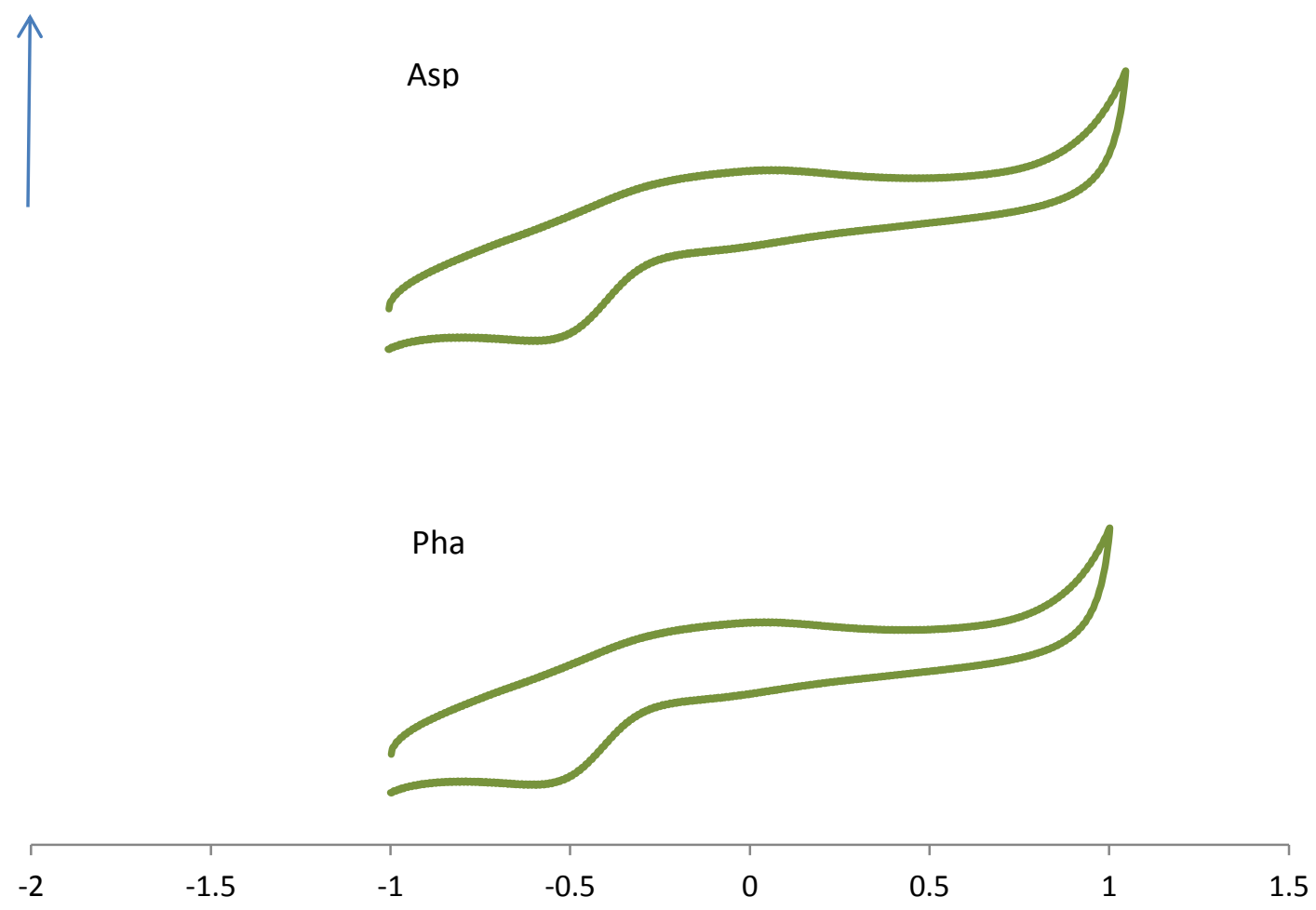

Fig. 5 

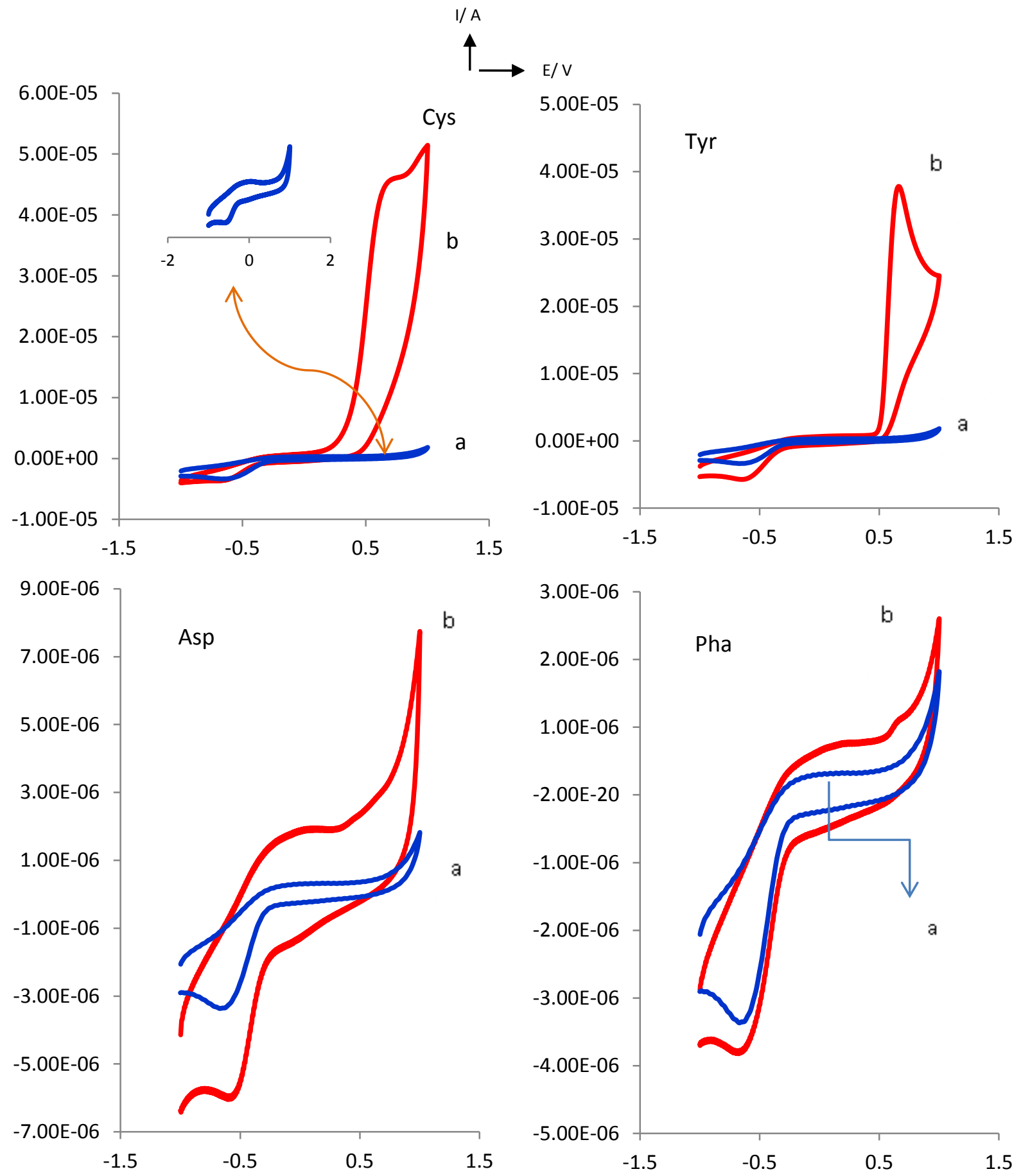

Fig. 6 

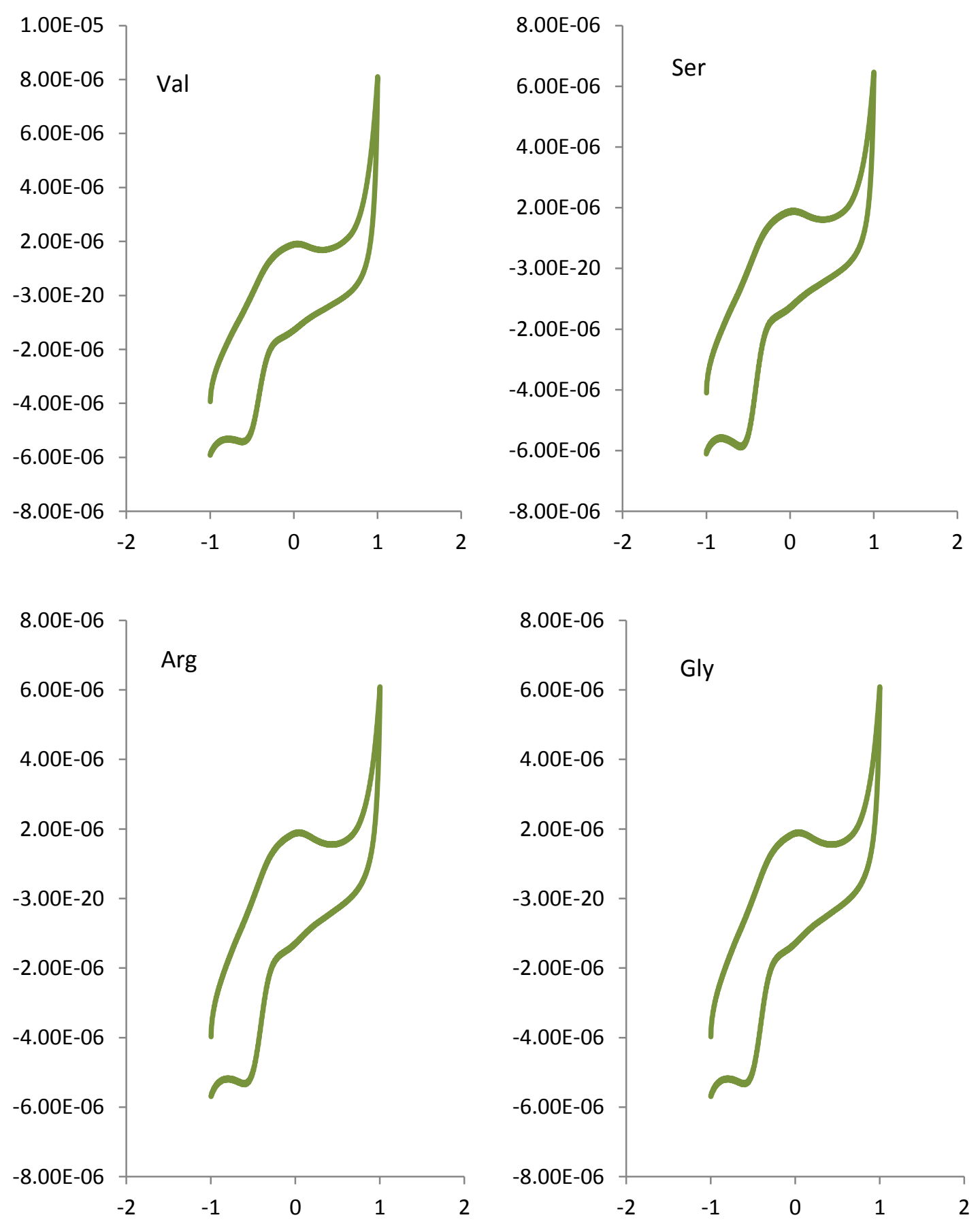

Fig. 7

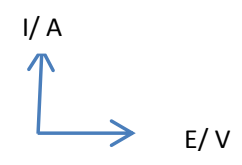



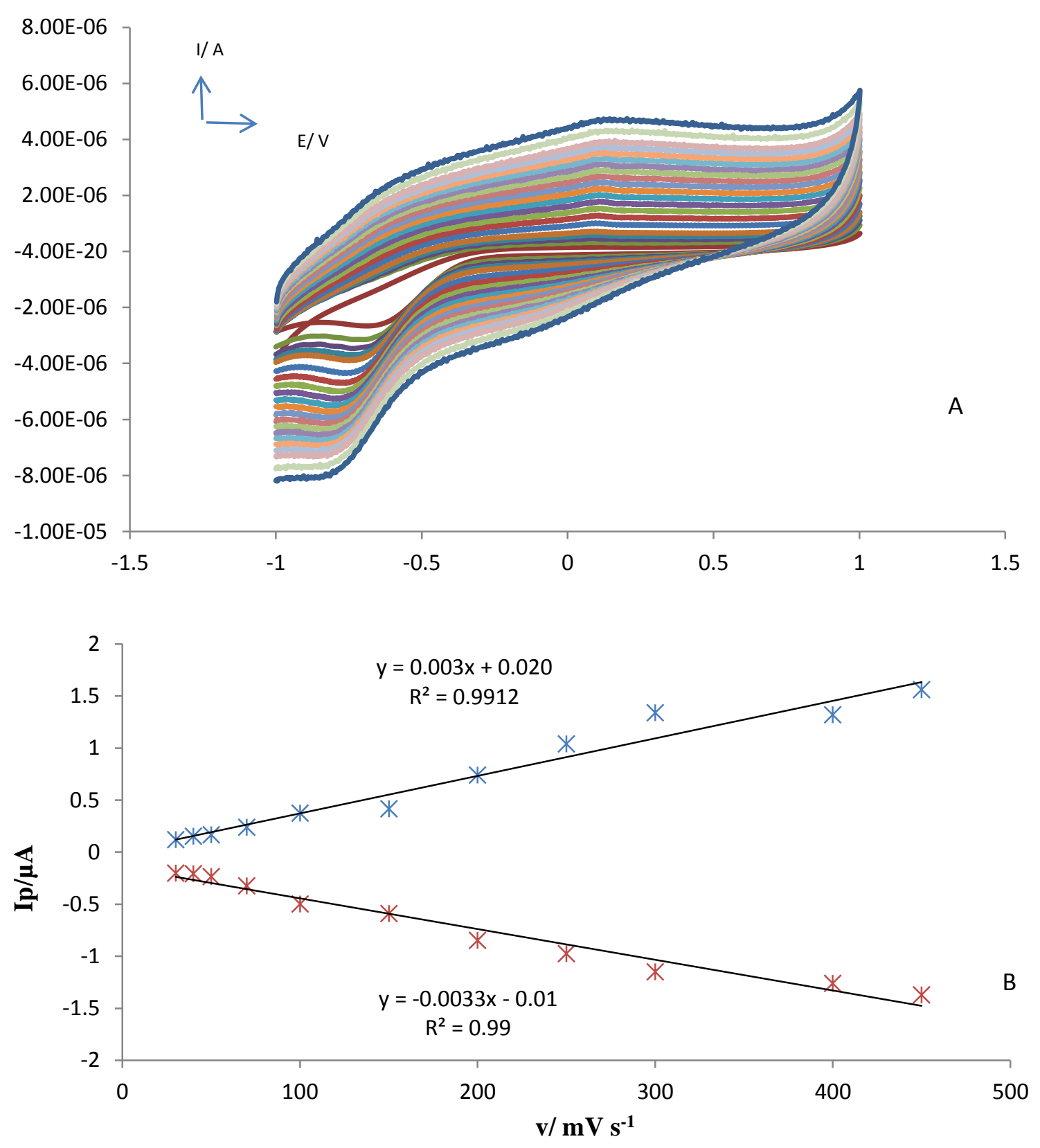

Fig. 8 

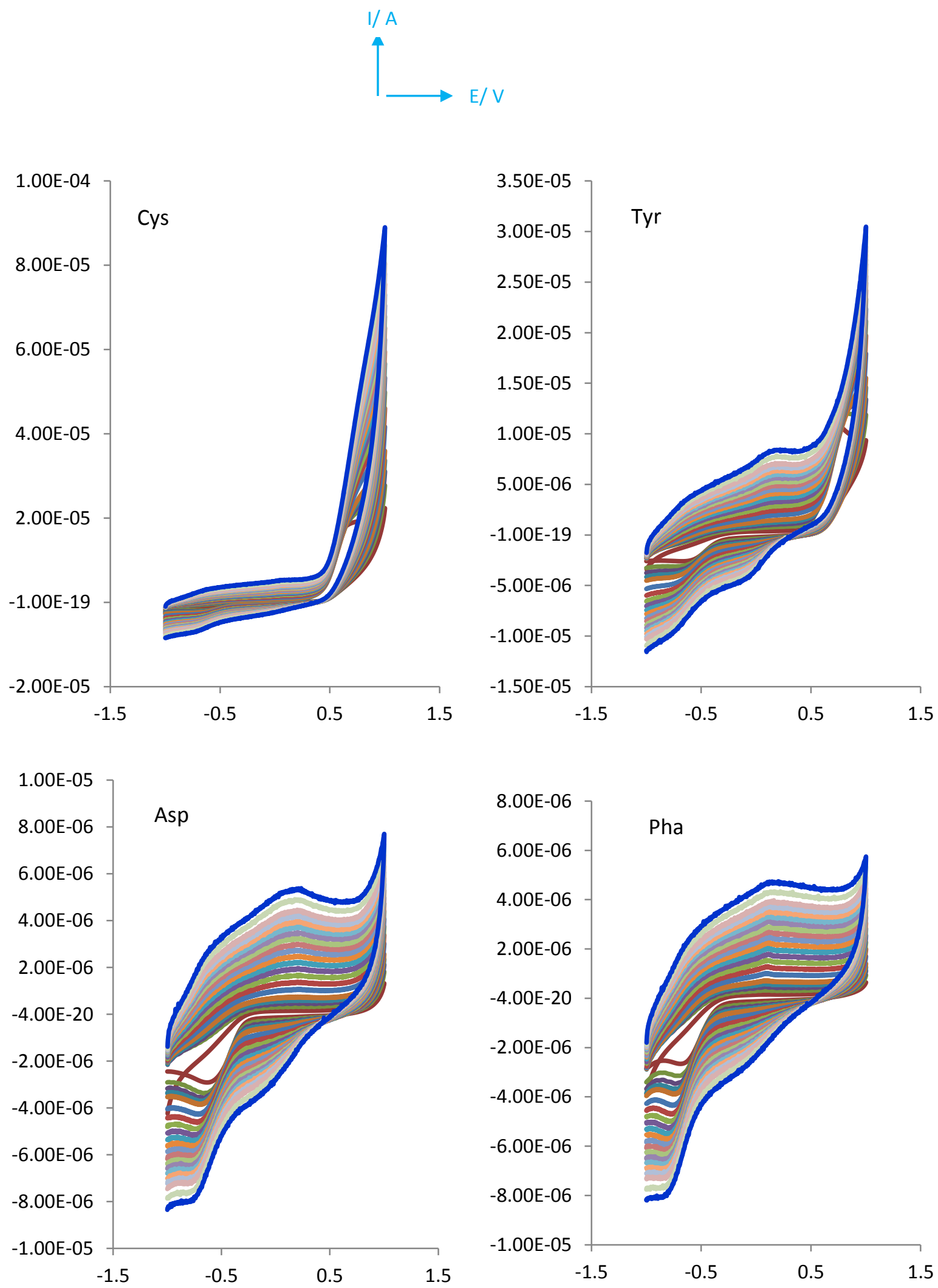

Fig. 9 

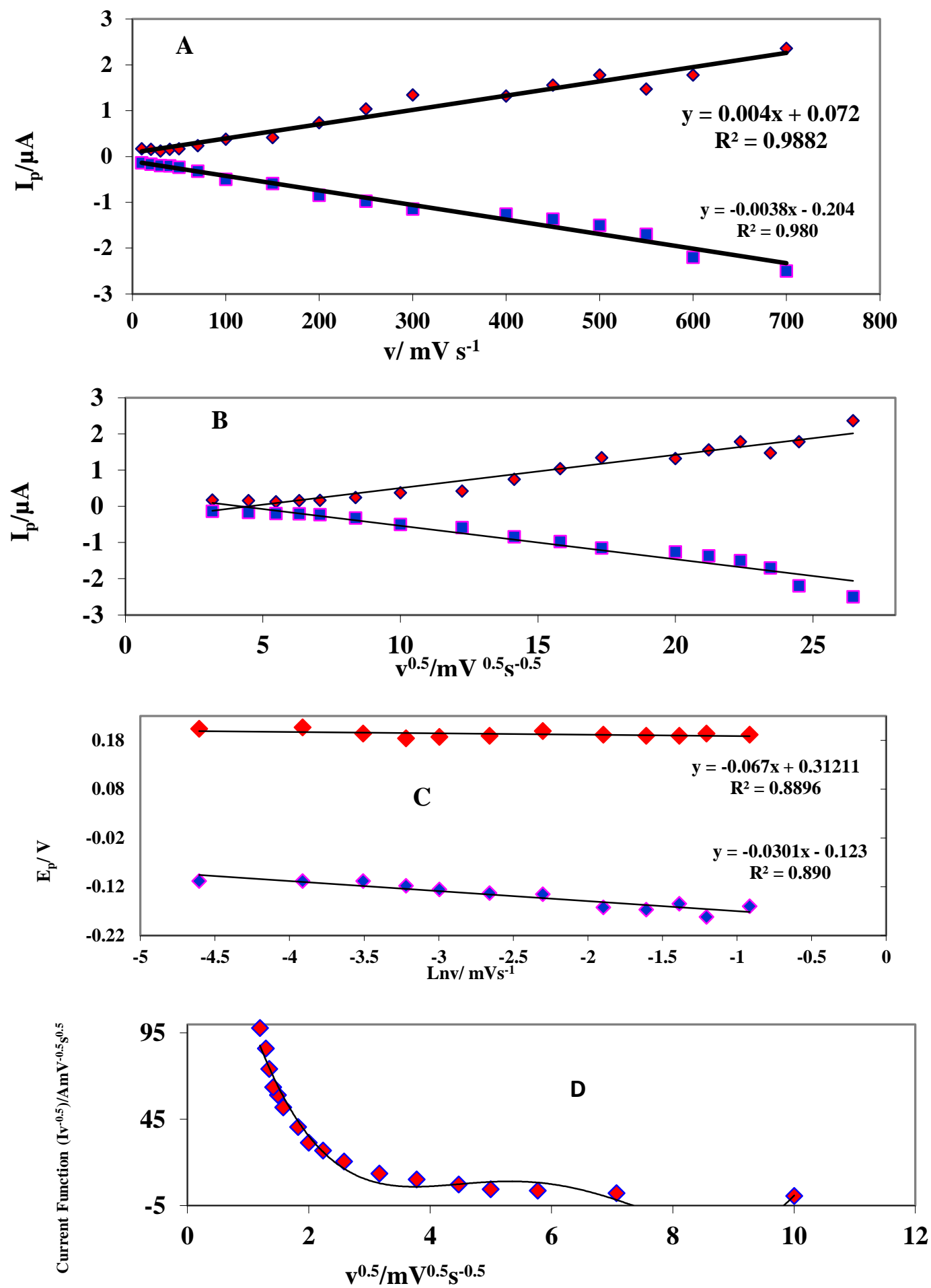

Fig. 10 

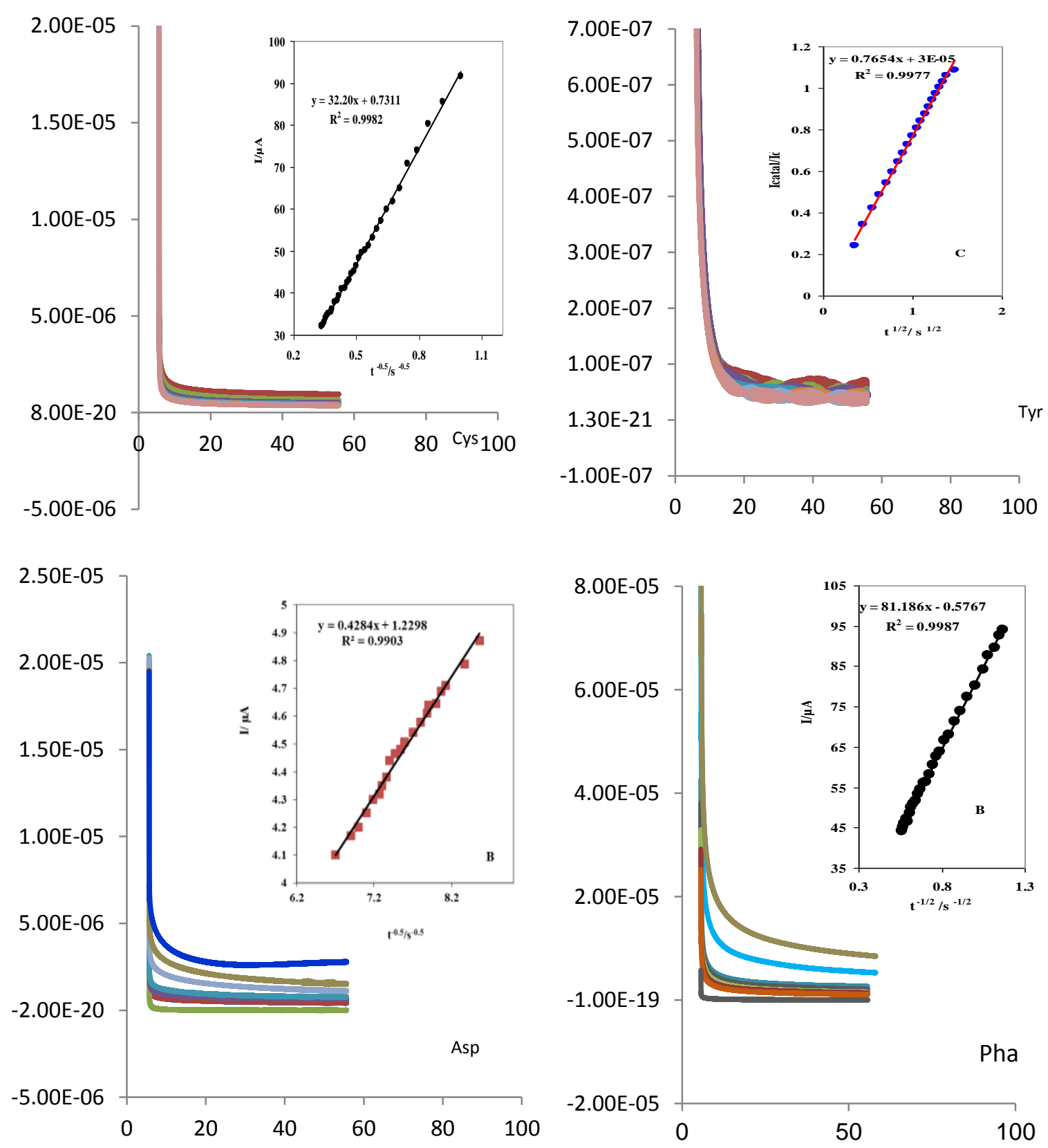

Fig. 11

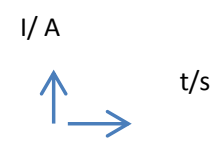



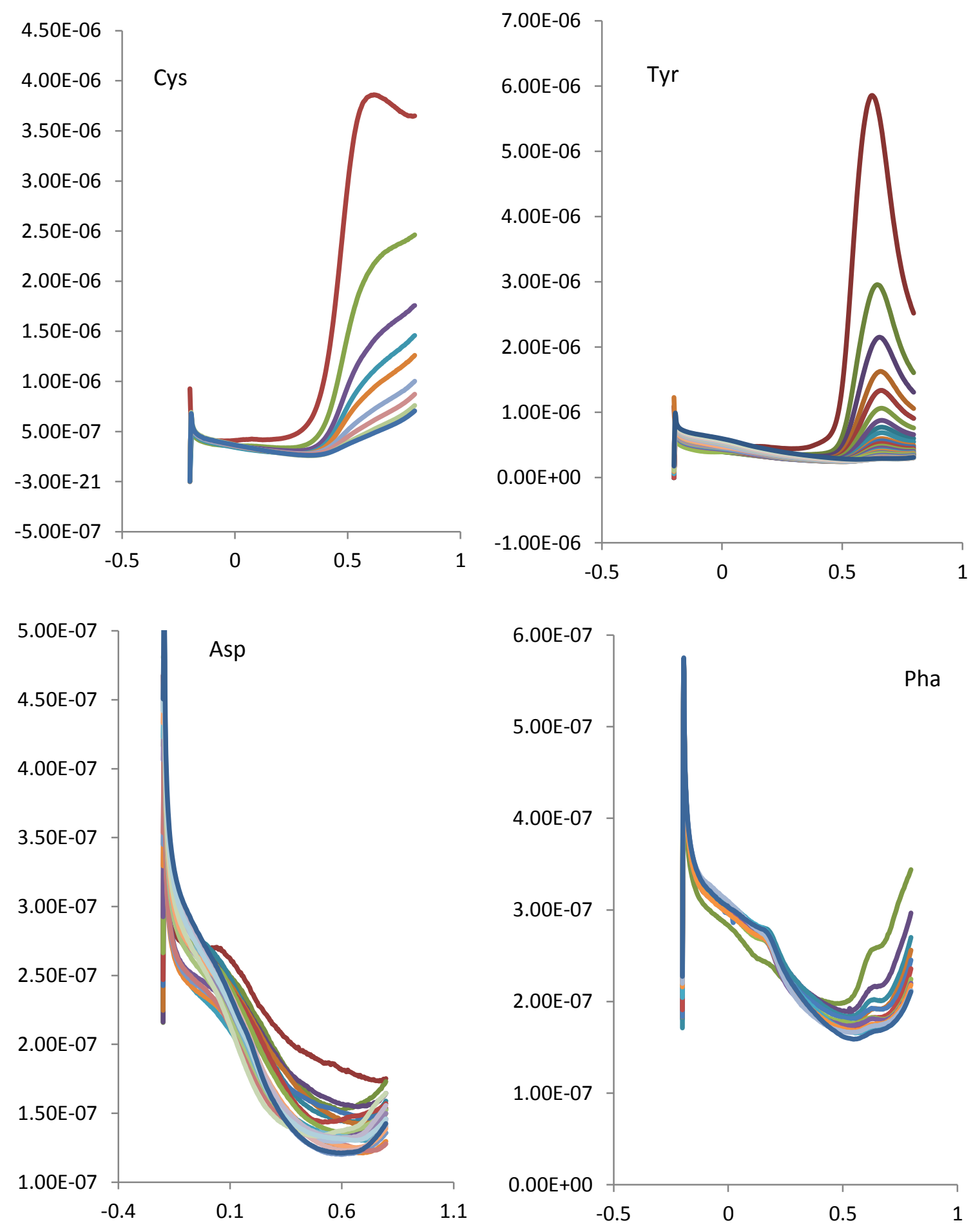

Fig. 12

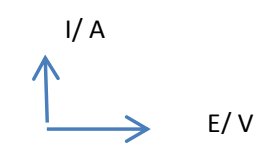



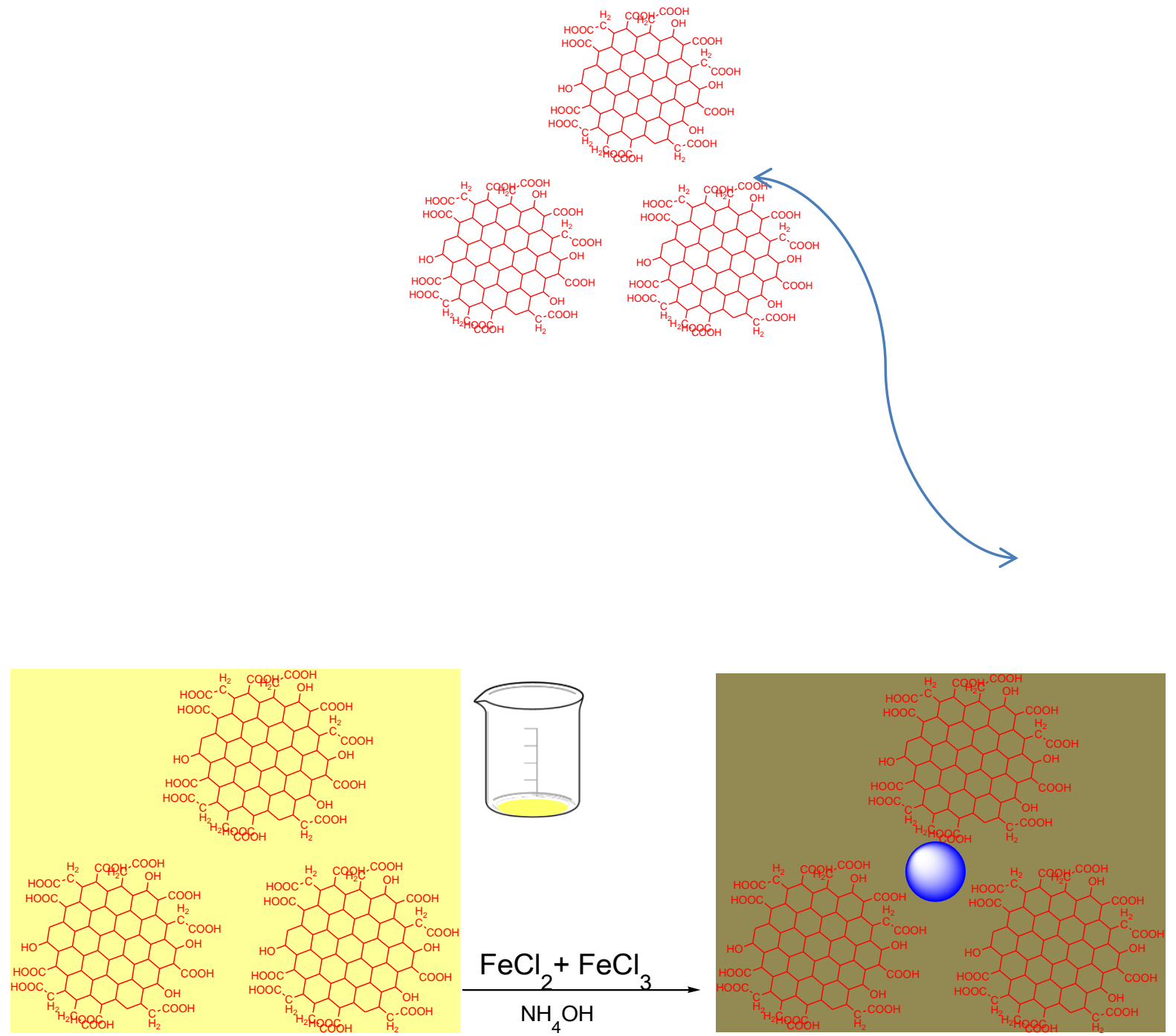

Scheme 1 


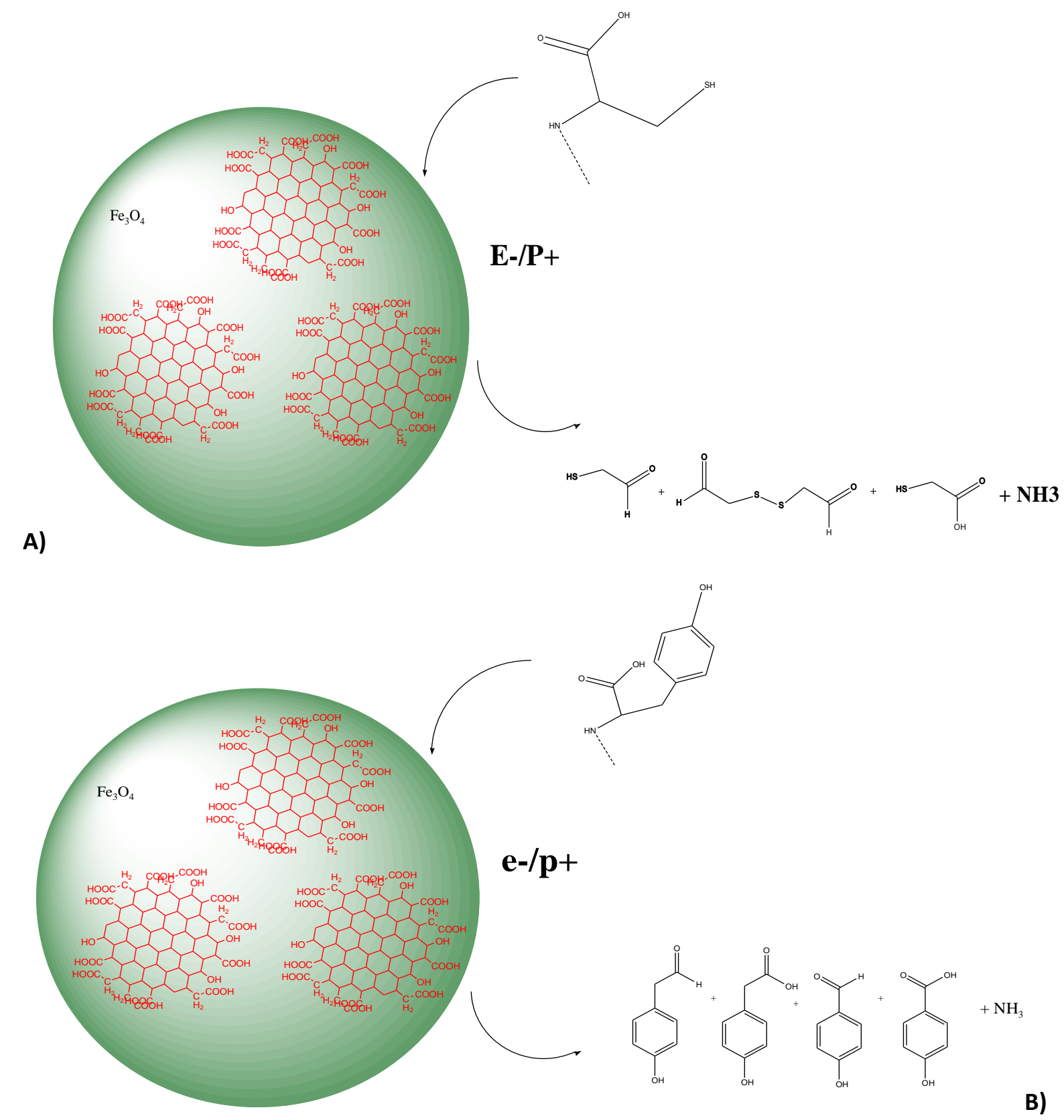



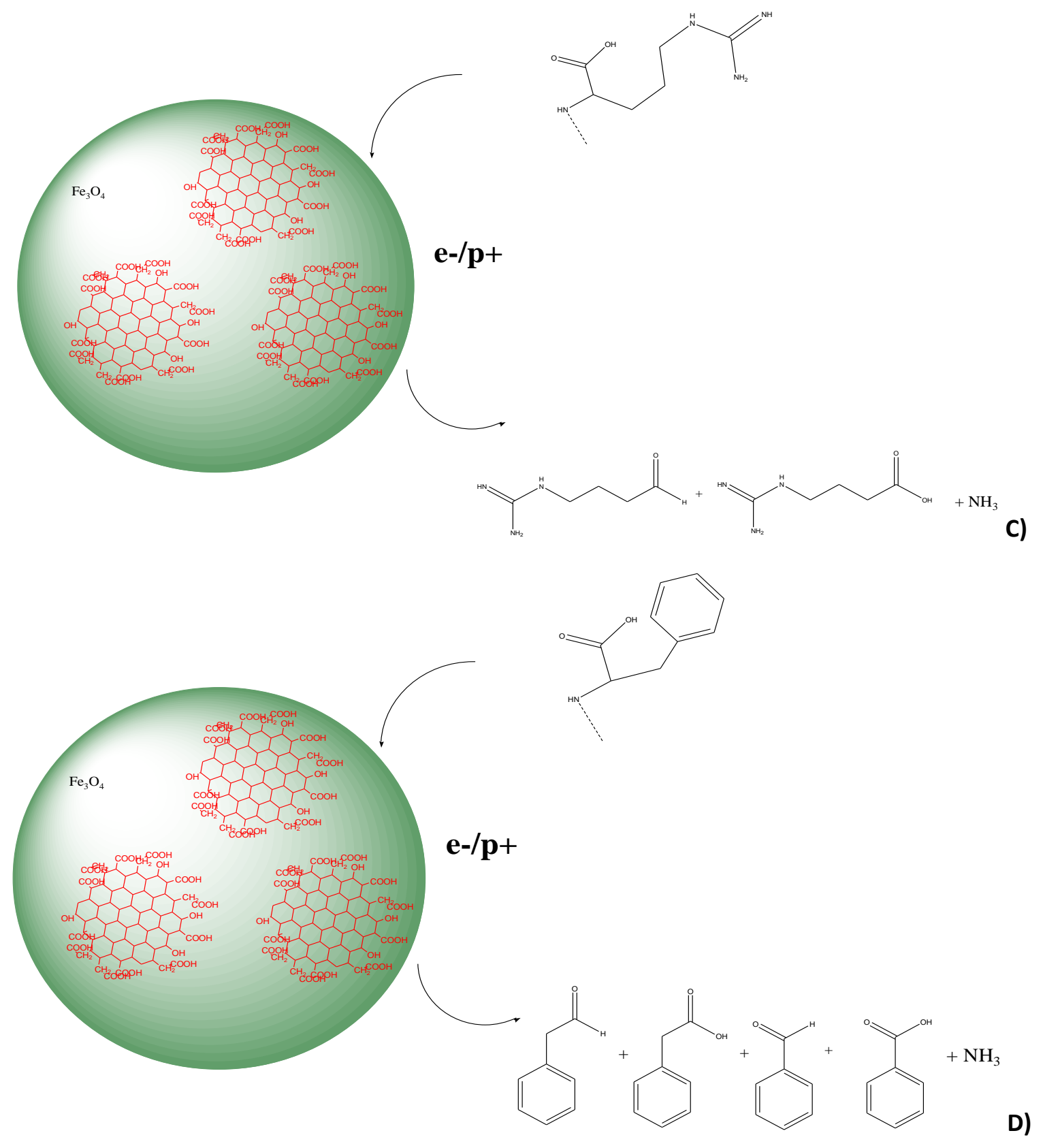

C)

Scheme 2 